\title{
A new approach to the synthesis of glycosides
}

\author{
Andrea Vasella \\ Institute of Organic Chemistry, University of Zurich, Winterthurerstrasse 190, CH-8057 \\ Zurich, Switzerland
}

\begin{abstract}
An new approach towards glycosides, which obviates the use of promoters and depends upon the acidity of the glycosyl acceptor is proposed to achieve regioselective glycosidation. Glycosylidene carbenes, generated under thermal or photolytic conditions from $\mathrm{O}$ benzylated or O-acylated 1-azi-glycoses, or from glycono-1,5-(or 1,4)-lactone tosylhydrazones react with hydroxy compounds to yield glycosides. The preparation of these precursors, their structure, their thermal stability, and their products of thermolysis are discussed. A mechanism is proposed to explain and predict the reaction of 1-azi-glycoses with mono-, di-, and triols. Protonation of the carbene in the $\sigma$-plane leads to an ion-pair, which cannot immediately form glycosides. The fate of this ion pair depends upon the pK of the glycosyl acceptor, inter- and intramolecular hydrogen bonds, the direction of $\mathrm{H}$-bonds, the presence of a neighbouring group at $\mathrm{C}(2)$, the configuration of the glycosyl acceptor, the solvent, and the temperature. Strongly acidic hydroxy compounds give glycosides in high yields and stereoselectively. Successful regio- and stereoselective glycosidation of diols and triols depends strongly upon intra- (and inter)molecular hydrogen bonds, both between the hydroxy groups of the acceptor and between functional groups of the donor and hydroxy groups of the acceptor. This is illustrated by a number of significant cases. For some of them, regioselectivity is complementary to the one observed in glycosidations of the Koenigs-Knorr-type, for others it is not. Reasons for this are discussed. Other cases present the preferential glycosylation of secondary hydroxy groups in the presence of a primary one, and the selective formation of $\alpha$-D-glycosides of AllNAc and GlcNAc.

Intramolecular reactions of alkoxyalkyl carbenes are illustrated by a new method for the formation of benzylidene acetals under basic conditions, and by a new synthesis of homobenzofurans. New reactions, leading to the formation of $C, C$ bonds at the anomeric centre are presented: the synthesis of spiro-oxiranes, of dialkoxy-spiro-cyclopropanes, and of the first glycosylated, enantiomerically pure derivatives of $\mathrm{C}_{60}$-buckminsterfullerene.
\end{abstract}

\section{INTRODUCTION}

Most current methods for the preparation of glycosides are based on the activation - by one or the other promoter - of a leaving group at the anomeric centre (ref. 1). A wide range of (potential) leaving groups has been proposed (ref. 2). Some of them are stable in the absence of a suitable promoter and function as a temporary protecting group (ref. 1c), others are very reactive (ref. 1a). The role of participating and non-participating protecting groups in determining anomeric selectivity is well understood, and the influence of participating solvents has become clearer (ref. 3). The importance of matching the relative reactivity of glycosyl acceptor and glycosyl donor to achieve diastereoselectivity has been recognised (ref. 4). The effect of protecting groups on the ease of formation of oxycarbenium ions - largely determining the reactivity of the glycosyl donor - has been exploited under the name of "armed" and "disarmed" donors (ref. 5). These results constitute impressive advances. In spite of them, the synthesis of oligosaccharides is far from routine, and important problems remain to be solved, such as the establishment of a standardised, repetitive method for the solid phase synthesis of oligosaccharides (ref. 6) and of a (generally applicable) method for a regioselective, nonenzymatic glycosidation, obviating (largely) the need for protecting groups (ref. 7).

Conceivably, these problems will be solved by using ever more sophisticated versions of the Koenigs-Knorr-type glycosylation. However, the systematic analysis of this type of glycosylation is difficult, due to the large variety of leaving groups, promoters, and reaction conditions. Regioselective glycosidation requires a method which takes advantage of the - presumably subtle - differences in the reactivity of hydroxy groups. A simplification of the reaction conditions (ref. 8) is therefore important.

\section{CARBENE PRECURSORS}

We have proposed a glycoside synthesis via glycosylidene carbenes with no promoter (ref. 9, 10). According to this concept (Scheme 1), a cyclic, carbohydrate-derived alkoxyalkylcarbene-ylide should be protonated by a hydroxy compound (ref. 11) to form an ion-pair, realising the simultaneous activation of a glycosyl donor and of a glycosyl acceptor. The ions should then combine to a glycoside. Regioselectivity might result in so far as the rate of protonation depends upon the (kinetic) acidity of individual hydroxy groups. 
Glycosylidene carbenes may be generated by thermolysis or photolysis either of ( $\mathrm{O}$-alkyl or $\mathrm{O}$-acyl protected) glycosylidene diazitines (ref. 9), or of the $\mathrm{Na}$ salts of glyconolactone tosylhydrazones (ref. 12, 13), or by photolysis of $\mathrm{O}$ acyl protected 1,1-diazides (ref. 14) (Scheme 2).

The synthesis of glycosylidene diazinines is illustrated in Scheme 3 which shows the preparation of the O-benzylated gluco-diazirine 1. It is obtained by oxidation of the corresponding diaziridines 6 , which are formed by treating glyconhydroximo-lactone sulfonates (such as 5) with ammonia. The sulfonate 5 is easily obtained from the oximes 3 via the glyconhydroximo-lactone 4. A number of other diazirines, such as 7-11 (ref. 9, 10, 15, 16) (see below) have been prepared by the same method.

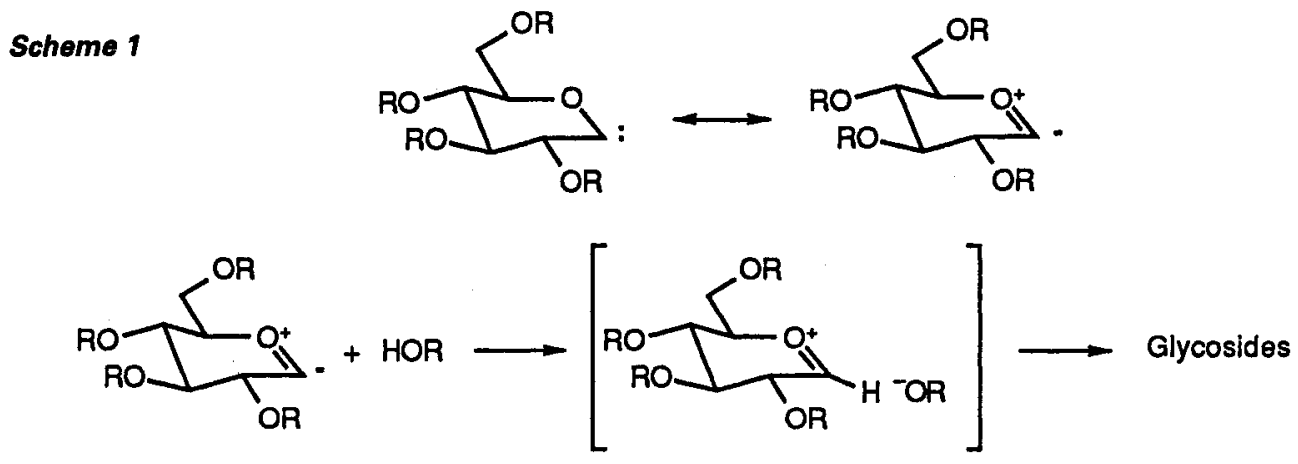

\section{Scheme 2}

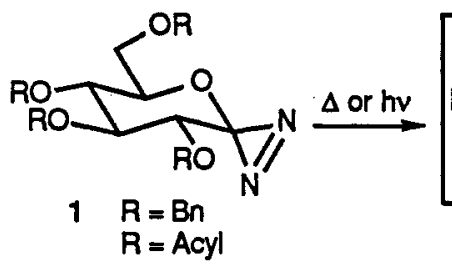

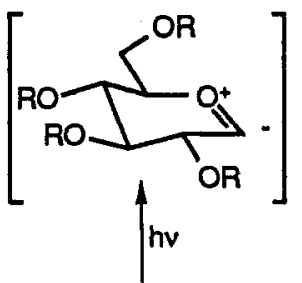
$\Delta$ or hv

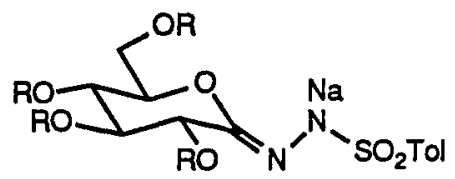

Na salt of $2 R=B n$ $R=$ Acyl

\section{Scheme 3}

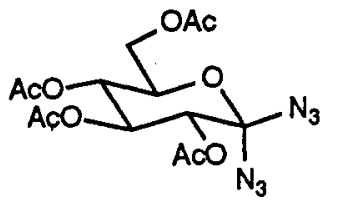

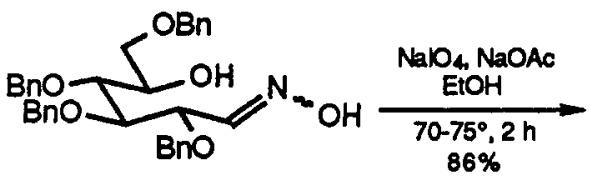

3

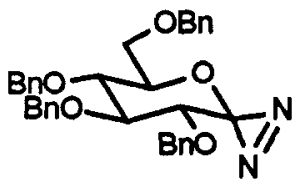

1 m.p. 50

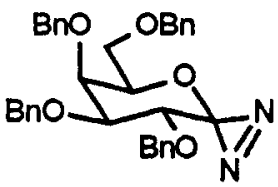

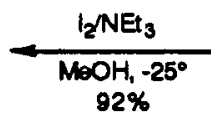

$92 \%$

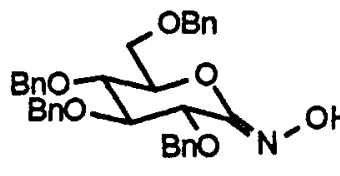

4 m.p. $88-89^{\circ}$

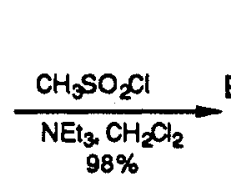
$98 \%$

5<smiles>CON1C(O)C(OCc2ccccc2)C(OCc2ccccc2)C(O)C1OCc1ccccc1</smiles>

5 m.p. $64-65.5^{\circ}$

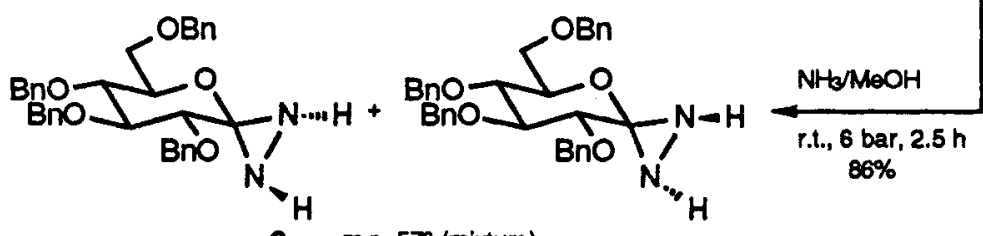

6 m.p. $57^{\circ}$ (mixture)

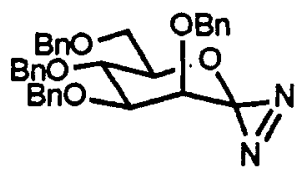

8

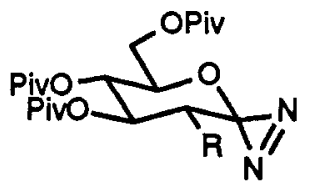

$9 \quad \mathrm{R}=\mathrm{H}$

$10 R=O P i v$

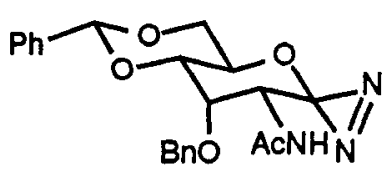

11 
Scheme 4 shows the synthesis of some alkyl- and acyl-protected lactone tosylhydrazones of the pyranose and the furanose series. These carbene precursors are more easily accessible than the diazirines. Particularly important is the possibility to prepare furanose-derived lactone hydrazones (ref. 17), as furanose-derived diazirines decompose at very low temperatures (ref. 9). However, lactone tosylhydrazones react less cleanly then diazirines and give lower yields. Toluenesulfinate, liberated during formation of the carbenes, frequently participates in the formation of products $(\rightarrow$ glycosylsulfones; ref. 12, 17).

\section{Scheme 4}
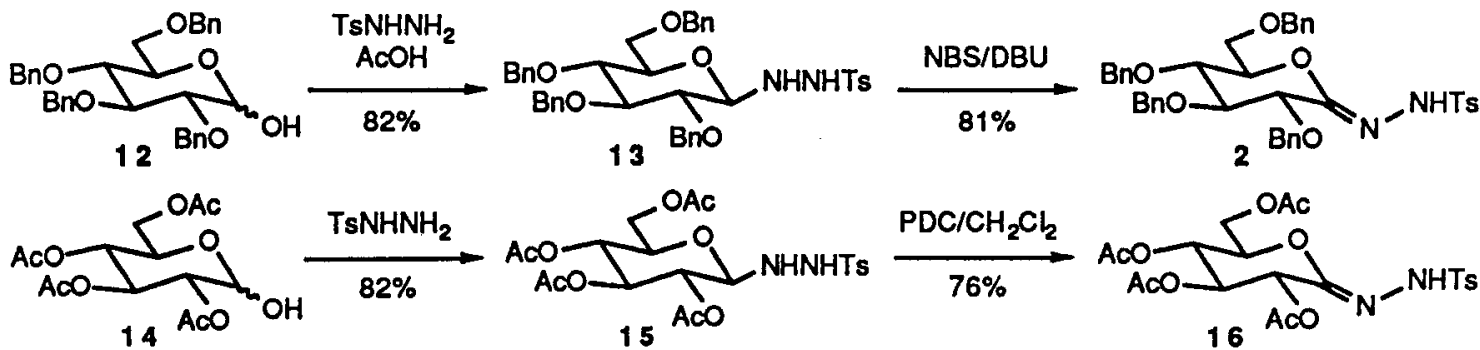

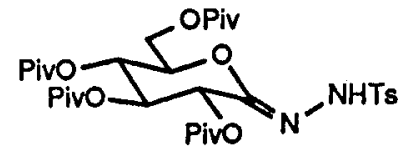

$1761 \%$ (2 steps)<smiles>O=C(Cc1ccccc1)C1C(COCc2ccccc2)OC(O)C1OCc1ccccc1</smiles>

20

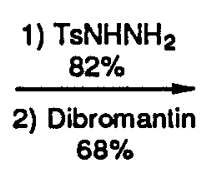

$68 \%$

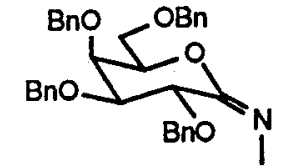

$1843 \%$ (2 steps) NHTs

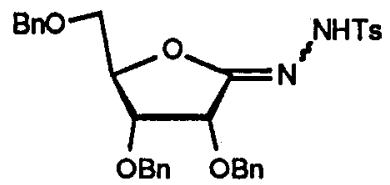

$21 E / Z 1: 7$

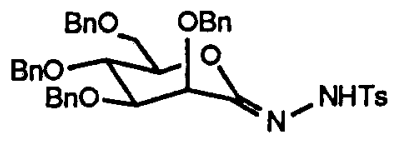

19 45\% (2 sleps)

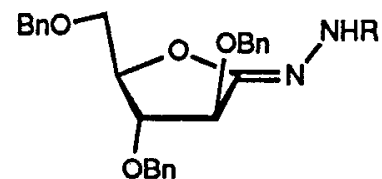

$22 \mathrm{R}=\mathrm{Ts}$

$51 \%$ (2 steps)

$23 R=2-$ Naphthylsulfonyl $51 \%$ (2 steps)
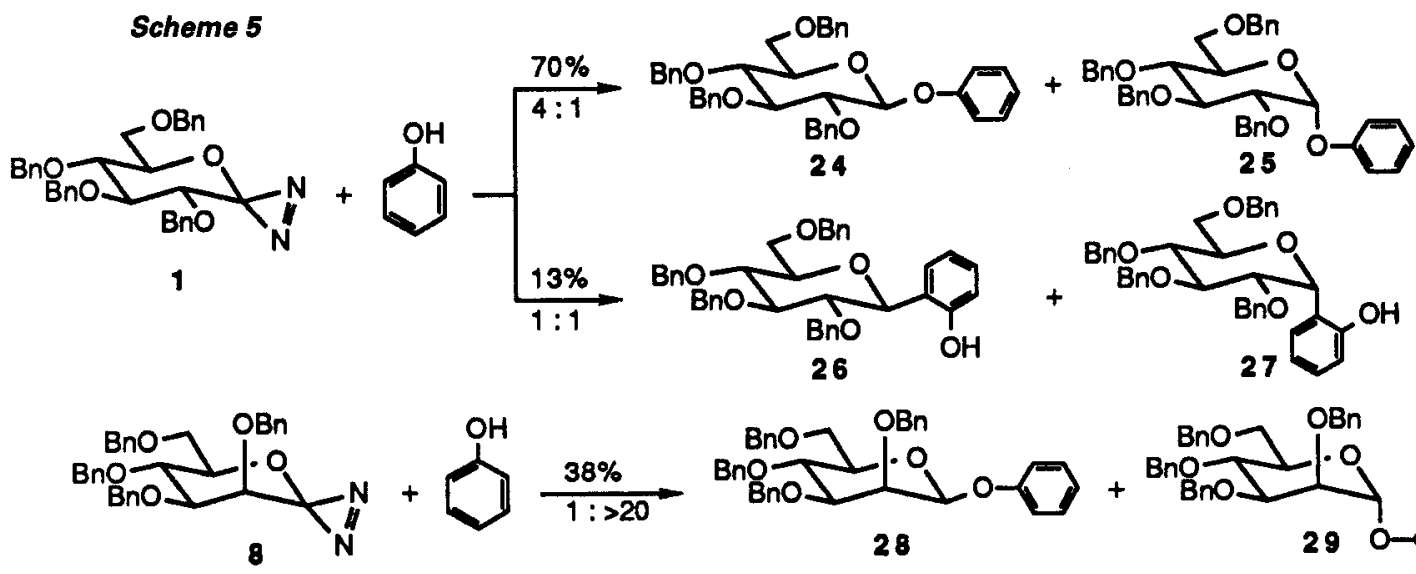

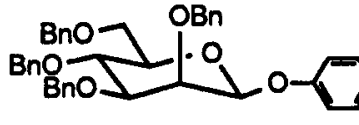

28

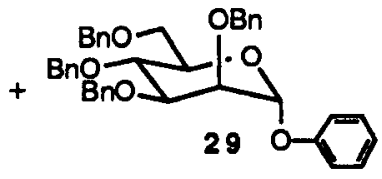

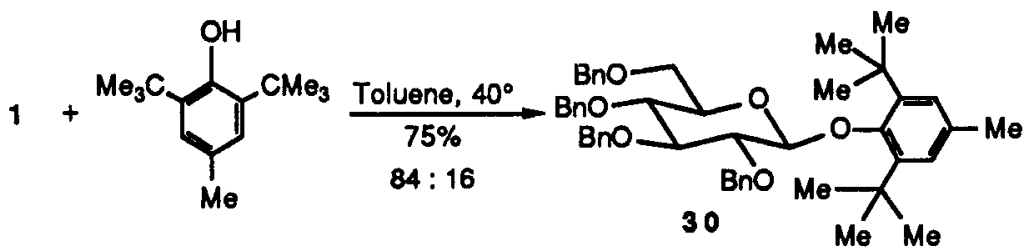<smiles>O=[N+]([O-])C1=CC(O)CC(O)C1[N+](=O)[O-]</smiles>

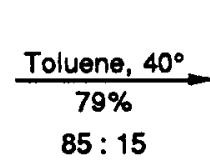

$85: 15$

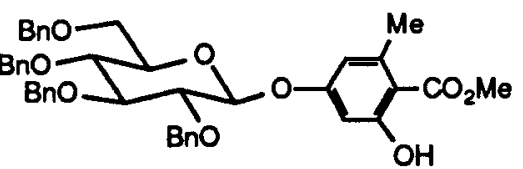

33
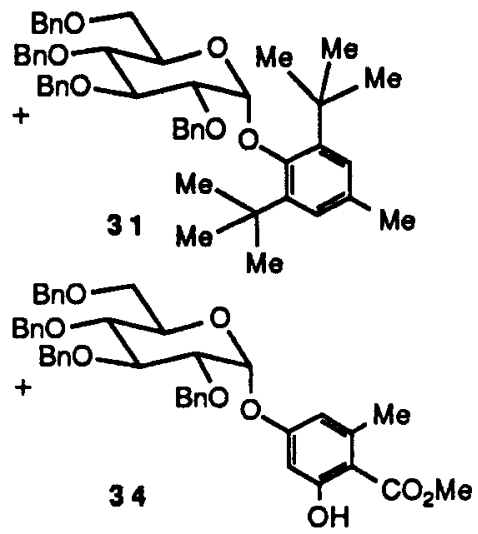


\section{GLYCOSYLATION OF PHENOLS AND OF MONOFUNCTIONAL ALCOHOLS}

Scheme 5 illustrates the results of the glycosidation of phenols with diazirines. Optimised yields (for equimolar amounts of diazirine and phenol) amount to 75-80\%. Main products are the 1,2-trans configurated O-glycosides, as demonstrated by the glycosidation of phenol by the gluco-and the manno-diazirines 1 and 8 , to yield mainly the $\beta$ - and $\alpha$-D-glycosides 24 and 29, respectively. Glycosidation of nucleophilic phenols leads regioselectively to C-glycosides as byproducts. Steric hindrance of the phenol has no bearing on the yields and on the diastereoselectivity, as demonstrated by the formation of $\mathbf{3 0}$ and $\mathbf{3 1}$. The regioselective glycosidation of methyl orsellinate (32) demonstrates that a hydroxy group which functions as a $\mathrm{H}$-bond donor in an intramolecular $\mathrm{H}$-bond is deactivated towards glycosidation; the monoglycosides $\mathbf{3 3}$ and $\mathbf{3 4}$ are obtained in good yields and again with a high degree of regioselectivity.

Scheme 6. Glycosidation of some monofunctional alcohols

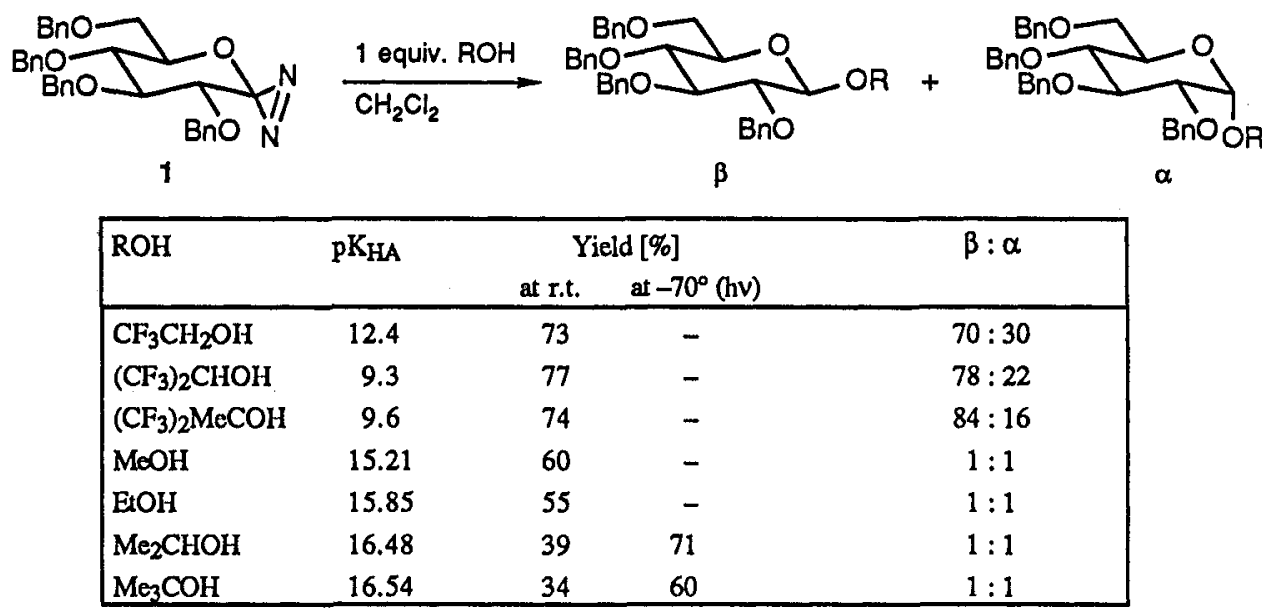

Monofunctional alcohols form two classes with regard to glycosidation by 1 (Scheme 6 ). Strongly acidic alcohols behave similarly to phenols. With $\mathrm{CH}_{2} \mathrm{Cl}_{2}$ as the solvent, 1,2-trans configurated glycosides are obtained as main products and in good yields. Relatively low yields of glycosides are obtained from weakly acidic alcohols when they are used in equimolar amount, in $\mathrm{CH}_{2} \mathrm{Cl}_{2}$, and at room temperature. Yields are much better at low temperature; the carbene is then generated by photolysis. There is no stereoselectivity. Both the yields and the stereoselectivity for the glycosidation of strongly acidic alcohols depend upon the solvent. Ethers, particularly DME, are superior to $\mathrm{CH}_{2} \mathrm{Cl}_{2}$, as

Scheme 7. Influence of the solvent on the glycosidation of a hindered strongly acidic alcohol

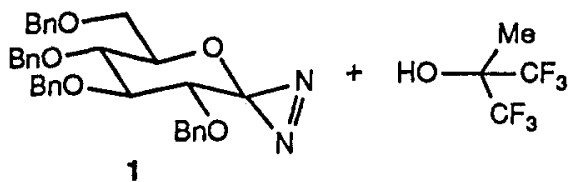

1

\begin{tabular}{|llr|}
\hline Solvent & Yield [\%] & $\alpha: \beta$ \\
\hline $\mathrm{CH}_{2} \mathrm{Cl}_{2}$ & 75 & $16: 84$ \\
toluene & 74 & $9: 91$ \\
dioxane & 76 & $5: 95$ \\
$\mathrm{THF}$ & 73 & $4: 96$ \\
DME & 80 & $2: 98$ \\
propionitrile & $54(16 \%$ of 36$)$ & $10: 90$ \\
propionitrile, $-60^{\circ}(\mathrm{hv})$ & $25(16 \%$ of 36$)$ & $13: 87$ \\
\hline
\end{tabular}

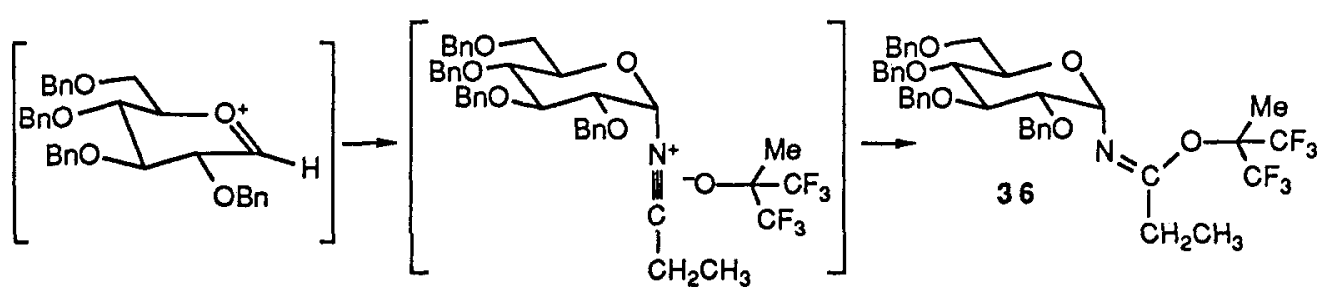


shown by the results in Scheme 7. These results (ref. 18) also demonstrate the absence of a significant influence of hindrance. Formation of the imidate 36 evidences solvation of an intermediate oxycarbenium ion by the nucleophilic solvent. In contrast to alcohols (ref. 3), the alcoholate attacks the nitrilium ion preferentially at the nitrilium-C, and not at the anomeric centre. Glycosylidene diazirines can be also used to prepare glycosides of long-chain, highly fluorinated alcohols (ref. 18, Scheme 8), which have attracted some interest as oxygen carriers (ref. 19).

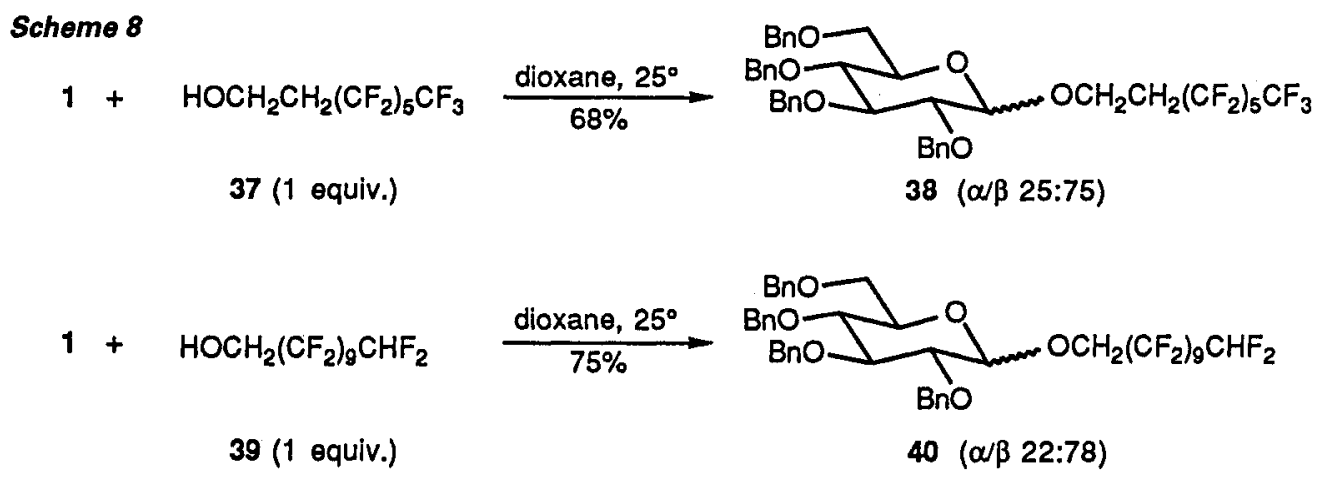

The outcome of the glycosidation of weakly acidic alcohols also depends upon the reaction conditions (Scheme 9). Thus, 1 reacts with 2-propanol in THF and at $-70^{\circ}$ to yield the anomeric glycosides 41 and 42 in a ratio of $92: 8$. Most significant are the glycosides $\mathbf{4 3}$ and 44 , isolated as byproducts of this reaction. They are products of the nucleophilic attack on the anomeric tetrahydrofuranylium ions $B$ and $C$ (ref. 7C, 18, 20). Together with the formation of the FriedelCrafts alkylation products $\mathbf{2 6}$ and 27 (Scheme 5) in the glycosidation of phenol and the formation of the imidate 36 (Scheme 7 , this constitutes strong evidence for the protonation of the intermediate carbene (ref. 11, 21) both by strongly and weakly acidic hydroxy compounds. We may thus advance a working hypothesis to explain the formation of 1,2-trans glycosides derived from strongly acidic hydroxy compounds both in weakly and in strongly coordinating solvents, the absence of stereoselectivity in the glycosidation of weakly acidic alcohols, and the formation of 1,2-trans (equatorial) glycosides derived from weakly acidic alcohols at low temperatures in THF as the solvent.

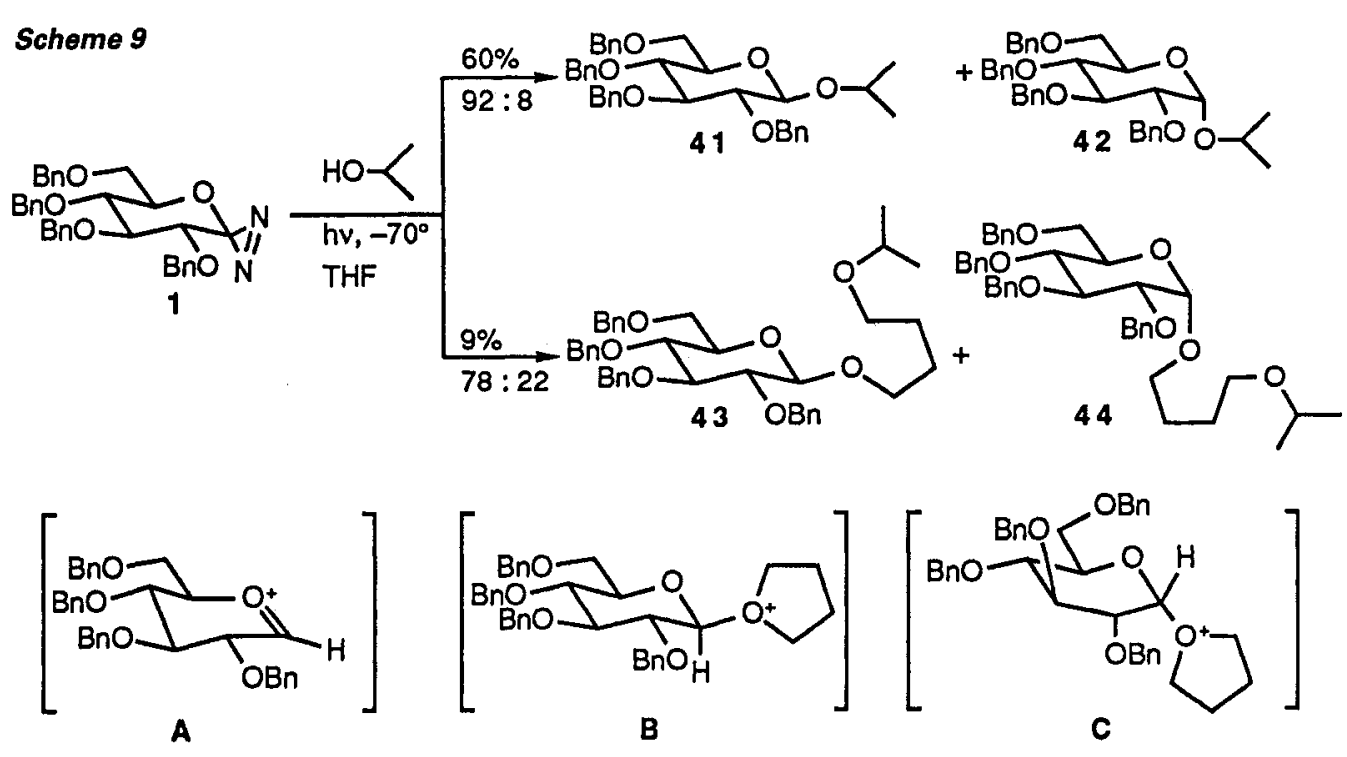

\section{WORKING HYPOTHESIS}

The working hypothesis is formulated in Scheme 10. Three steps may be distinguished. In the first one, formation of the glycosylidene carbene is initiated by heterolysis of one of the $\mathrm{C}-\mathrm{N}$ bonds of the diazirine. This leads to an intermediate zwitterion $\mathbf{A}$ with a cationic character at the anomeric centre. This zwitterion should rapidly lose nitrogen. In the second step, the resulting carbene $\mathbf{B}$ is protonated by the hydroxy compound to yield an ion pair $\mathbf{C}$. This protonation takes place in the $\sigma$-plane of the carbene. It is important to realise that the third step, the combination of the ions to form the glycoside takes place by attack of the oxy-anion in the $\pi$-plane of the oxycarbenium ion. Unless special conditions are fulfilled (see below!), the third step is a priori not concerted with the second one. Solvation of the ions becomes an important issue. 


\section{Scheme 10}

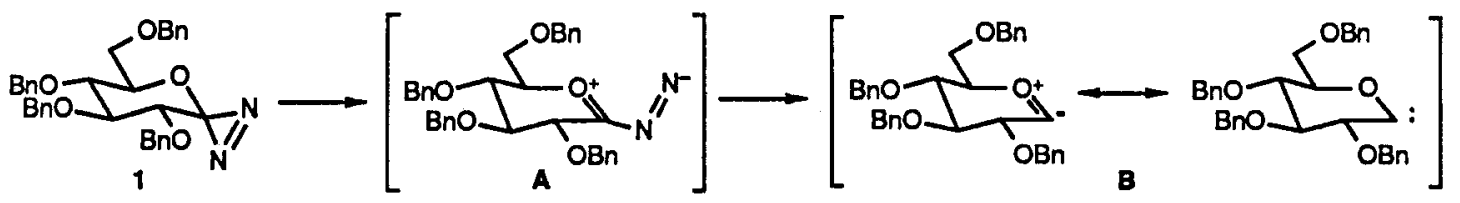

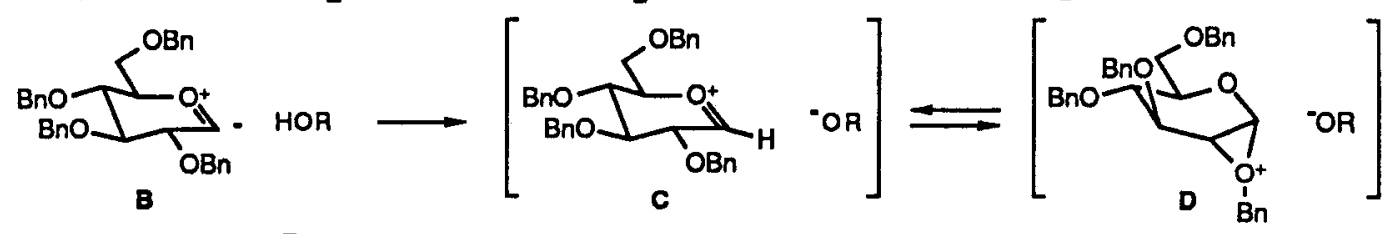

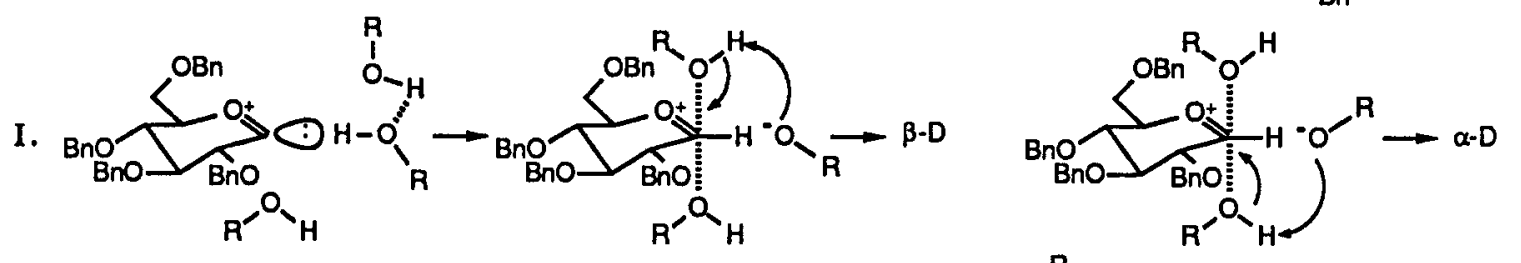

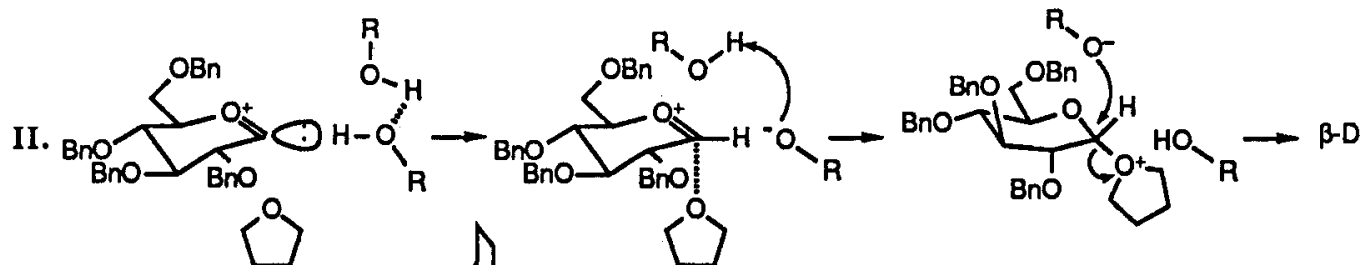

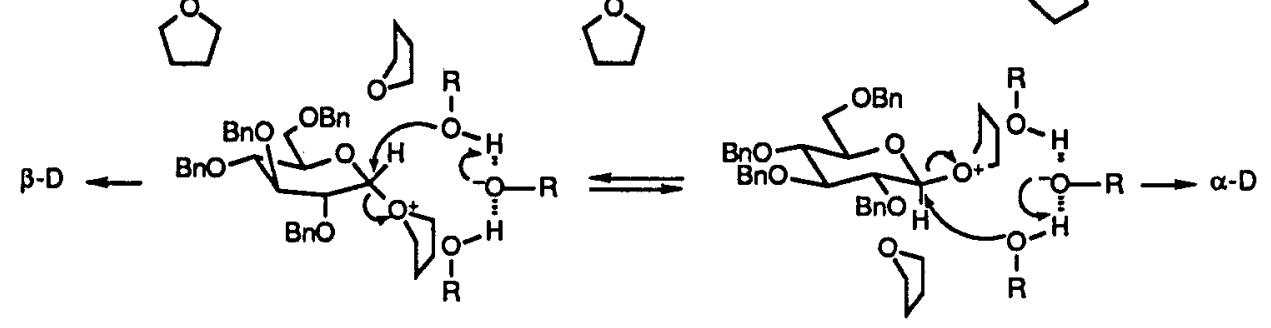

Strongly acidic, and thus poorly nucleophilic alcohols will only weakly solvate the oxycarbenium ion. If they are glycosylated in a poorly coordinating solvent, the $\mathrm{C}(2)$-benzyloxy group will be the best nucleophile in the neighbourhood of the cationic centre and solvate it. As a rule, this participation of the benzyloxy group is not observed for glycosylations of the Koenigs-Knorr-type. In Scheme 10, it is indicated in an extreme way (D). This participation directs the approach of the oxy-anion trans to the C(2)-benzyloxy group.

More strongly acidic alcohols lead to a faster protonation of the carbene (ref. 21). One therefore expects that oligomeric alcohol (ref. $11 \mathrm{~m}, 11 \mathrm{n}$ ) will protonate the carbene faster then monomeric alcohol. This is illustrated in the second part (I.) of Scheme 10. It illustrates that weakly acidic and thus relatively nucleophilic alcohols are expected to solvate the oxycarbenium ion more efficiently than the $\mathrm{C}(2)$-benzyloxy group. The oxy-anion, derived from the protonating species cannot (directly) attack the oxycarbenium centre, being located in the $\sigma$-plane. However, rapid H-transfer from a hydrogen bonded neighbour (ref. 22) may generate an oxy-anion, correctly positioned for attack in the $\pi$-plane above or below of the cationic centre, to which it may already be coordinated. Either side of the cationic centre may be attacked. The newly generated oxycarbenium ion may also be solvated by the nucleophilic solvent of which the axial attack should be stereoelectronically favoured (Scheme 10,II.). This generates an $\alpha$-D-configurated tetrahydrofuranylium ion, which, due to the reverse anomeric effect (ref. 23) may be more reactive then the equatorial anomer. At a low temperature, attack of the oxy-anion on the initially formed tetrahydrofuranylium ion leads preferentially to the

\section{Scheme 11}
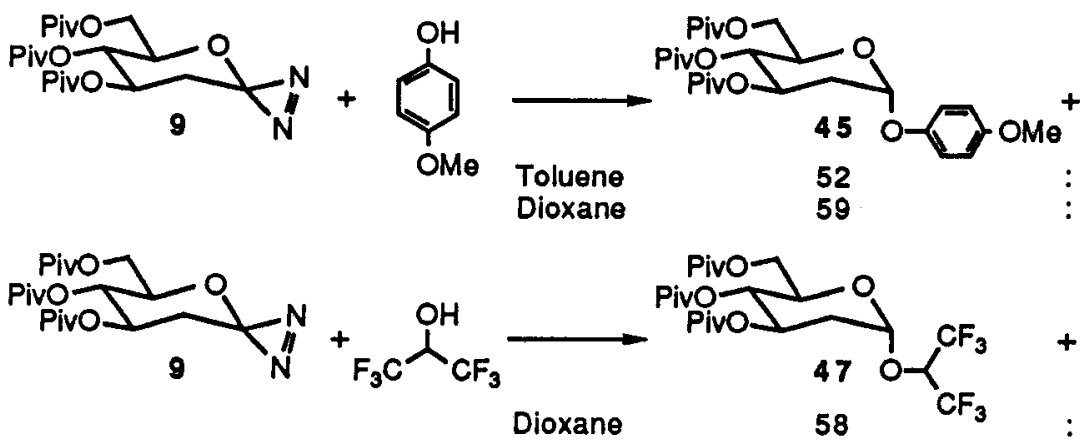

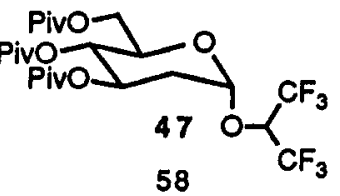

58

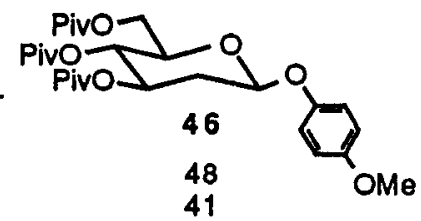

41

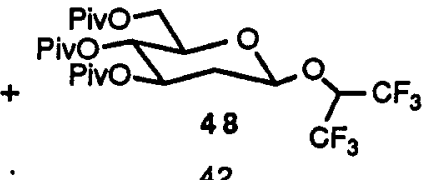


equatorial glycoside; at higher temperatures, one expects equilibration of the tetrahydrofuranylium ions, with substantial loss of stereoselectivity.

As shown in Scheme 11, the neighbouring group participation of the benzyloxy group is evidenced by the poor stereoselectivity in the glycosidation of 4-methoxyphenol and of hexafluoro-2-propanol with the diazirine 9, derived from 2deoxyglucose. At best, there is a weak preference for the axial, 1,2-cis configurated glycosides 45 and 47 (ref. 24).

Scheme 12. Thermolysis of diazirines and activation energy at $25^{\circ}$

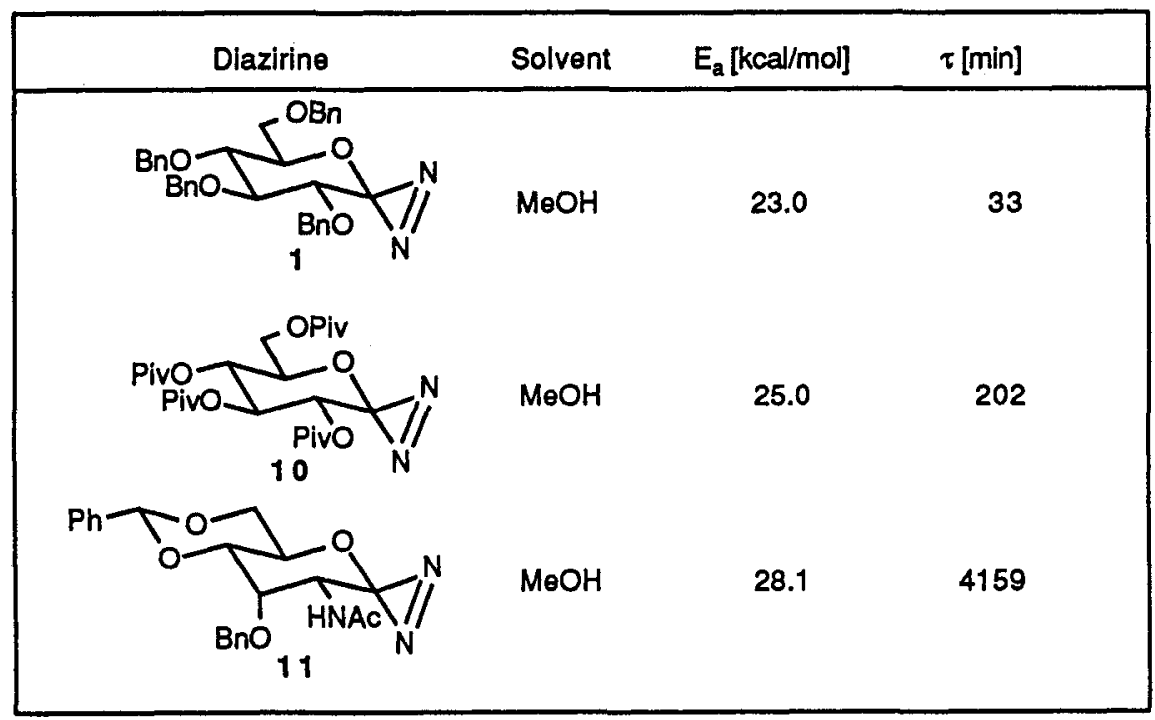

From a practical point of view, one should be able to predict the stability of these diazirines. The initial transformation of 1 into a zwitterion A, possessing a cationic character at the anomeric centre means that all the factors which destabilise a glycosyl cation will stabilise an alkoxyalkyl diazirine. We have measured the activation energy (first order kinetics) for the thermolysis (ref. 25) of the diazirines 1,10, and 11 in methanol (Scheme 12). There is a significant difference between the activation energies of these diazirines at $25^{\circ}$ (ref. 26), in keeping with the stronger $\sigma$-acceptor properties of the pivaloyloxy and the acetamido groups, as compared to benzyloxy groups, and with the strain imposed upon a glycosyl cation in the trans-trioxadecalin system (ref. 27). Ideally, one would compare the length of the two $\mathrm{C}-\mathrm{N}$ bonds of each 1,10, and 11 to find evidence for a preferred initial cleavage of one of these bonds. Only 11 yielded crystals suitable for X-ray analysis (ref. 28). There is a small difference for the bond lengths $(<3 \sigma)$. The "pseudoaxial" bond is slightly longer, as one might expect.

Scheme 13

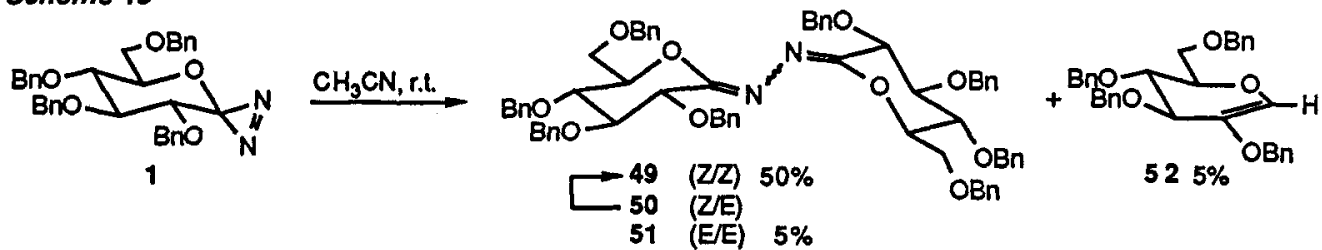

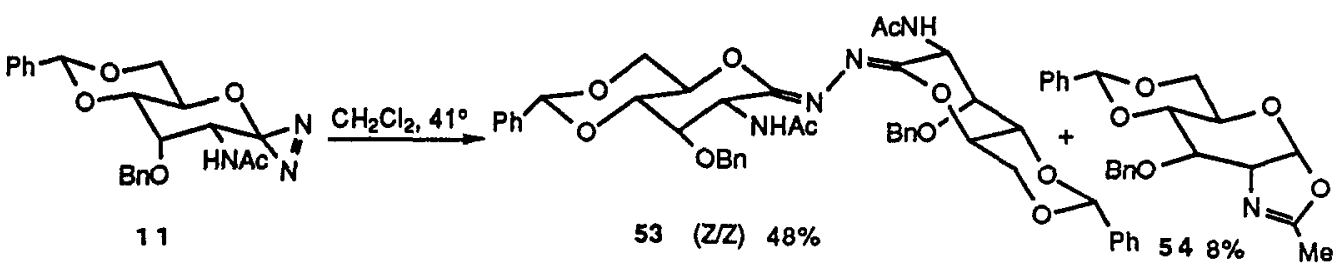

The main products of thermolysis of 1-azi-glycoses in non-hydroxylic solvents (ref. 26) are lactone azines (Scheme 13), derived from the interaction of carbenes with diazirines (ref. 29). At room temperature, 1 leads to a mixture of the $(Z / Z),(Z / E)$, and $(E / E)$ configurated isomers 49-51. The unstable $(Z / E)$ configurated 50 transforms into the major $(Z / Z)$ isomer 49 . Very little of 52 , the product of $\mathrm{H}$-migration, is formed. Thermolysis of 11 , necessarily at a somewhat higher temperature, leads exclusively to the $(Z / Z)$ azine 53 and to small amounts of the oxazolidine 54, presumably derived from the intermediate carbene by protonation and neighbouring group participation. These products of thermolysis are also observed as byproducts of reactions with weakly reactive partners. 


\section{GLYCOSYLATION OF DIOLS AND TRIOLS}

Glycosylation of monofunctional alcohols and of phenols by 1-azi-sugars shows a strong influence of the (kinetic) acidity of hydroxy compounds on yields and stereoselectivity. Regioselective glycosidation ought to succeed when there is a relatively large difference in the degree of acidity of hydroxy groups. As indicated by the regioselective glycosylation of orsellinate (Scheme 5), intramolecular H-bonds may lead to a differentiation of hydroxy group reactivity and to a high degree of regioselectivity. For mono- and oligosaccharides, which are less acidic than phenols, one ought to look for hydroxy groups which function as H-bond acceptors. Such hydroxy groups possess an increased kinetic acidity, which should be more important for a successful glycosidation via carbenes than the concomitant lowered degree of acidity for H-bond donating hydroxy groups (ref. 30). This is evidenced by the glycosylation of diisopropylideneglucose (55) by 1 equivalent of 1 in toluene (Scheme 14). Although the reaction yields $73 \%$ of the glycosides 56 and 57 , it proceeds with an unsatisfactory degree of selectivity $(\beta-D / \alpha-D 2: 1)$ (ref. 18).

Scheme 14
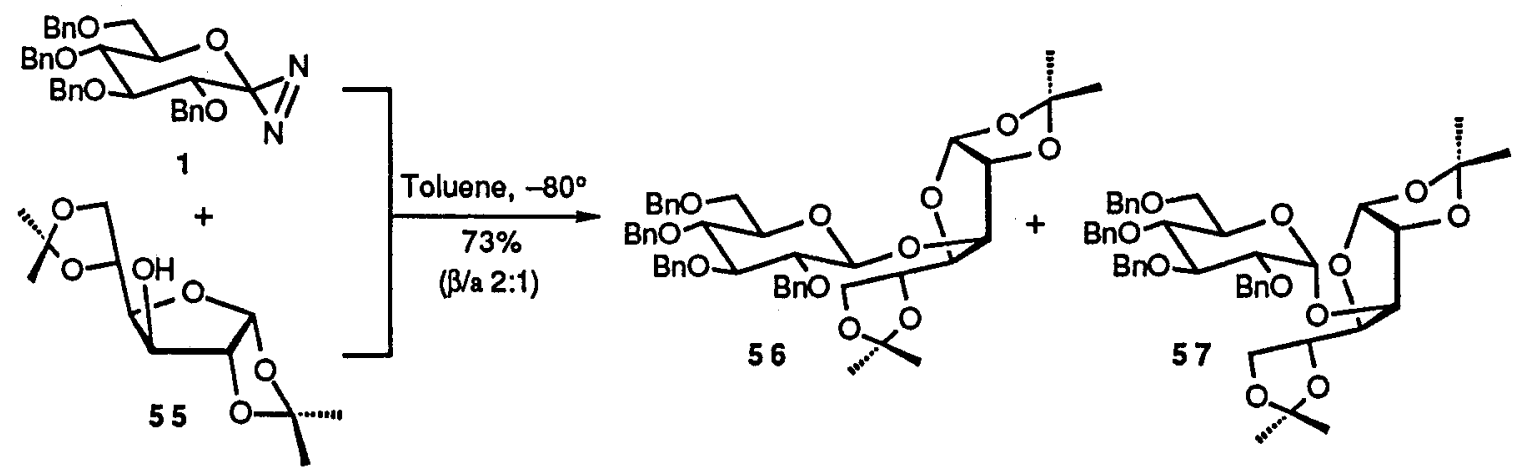

To predict the existence of (relatively) strong H-bonds for partially protected saccharides in organic solvents, we started from the observation that intramolecular $\mathrm{H}$-bonds in crystals of saccharides are much less frequent than intermolecular ones (ref. 30 p. 149 and p. 169 ff., 31). Hence, intramolecular H-bonds in crystals indicate relatively strong intramolecular H-bonds, which may persist in solution. A second parameter, directly relevant to the existence of intramolecular $\mathrm{H}$-bonds in solution, is given by the shift to lower frequencies and by the broadening of $\mathrm{O}-\mathrm{H}$ absorption bands in the IR spectra of dilute solutions of alcohols (ref. 30 p. 50 ff., 32).

Scheme 15. Intramolecular H-bonds from $X$-ray analysis and IR spectroscopy

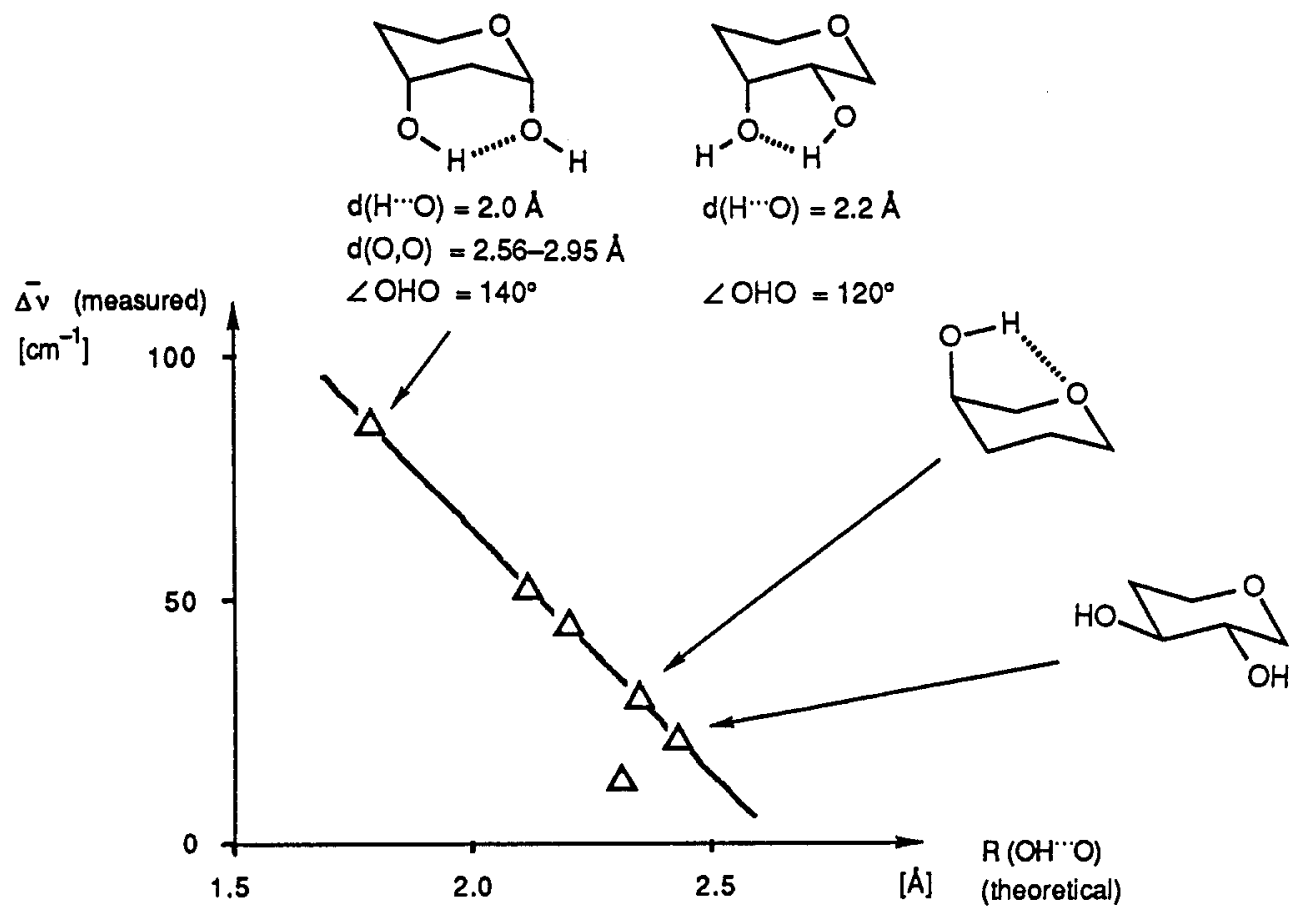

Scheme 15 (modified from ref. 32) shows a correlation of IR band shifts, $(\mathrm{OH}$... 0 )-distances, and the relative orientation of $\mathrm{H}$-bond donor and acceptor groups in pyranoses. According to this correlation, we expect the best regio- 
selective glycosidations for 1,3-diaxial diols. Regioselectivity should be lower for 1,2-cis-diols and for diols possessing one axial hydroxy group in position 2 or 4. Regioselective glycosidation of equatorial 1,2-trans-diols ought to be difficult.
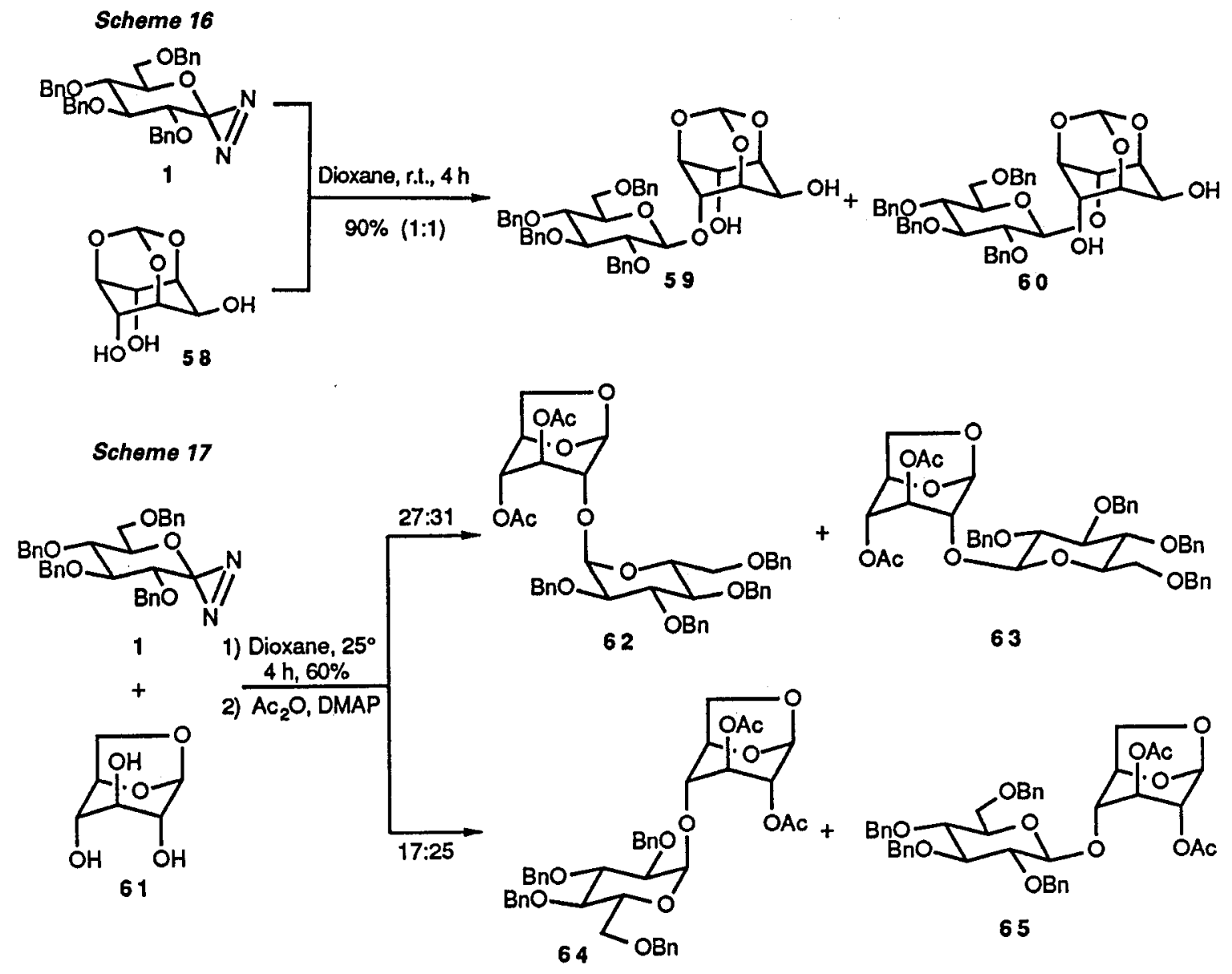

Scheme 18. X-ray structures of 58 and 61

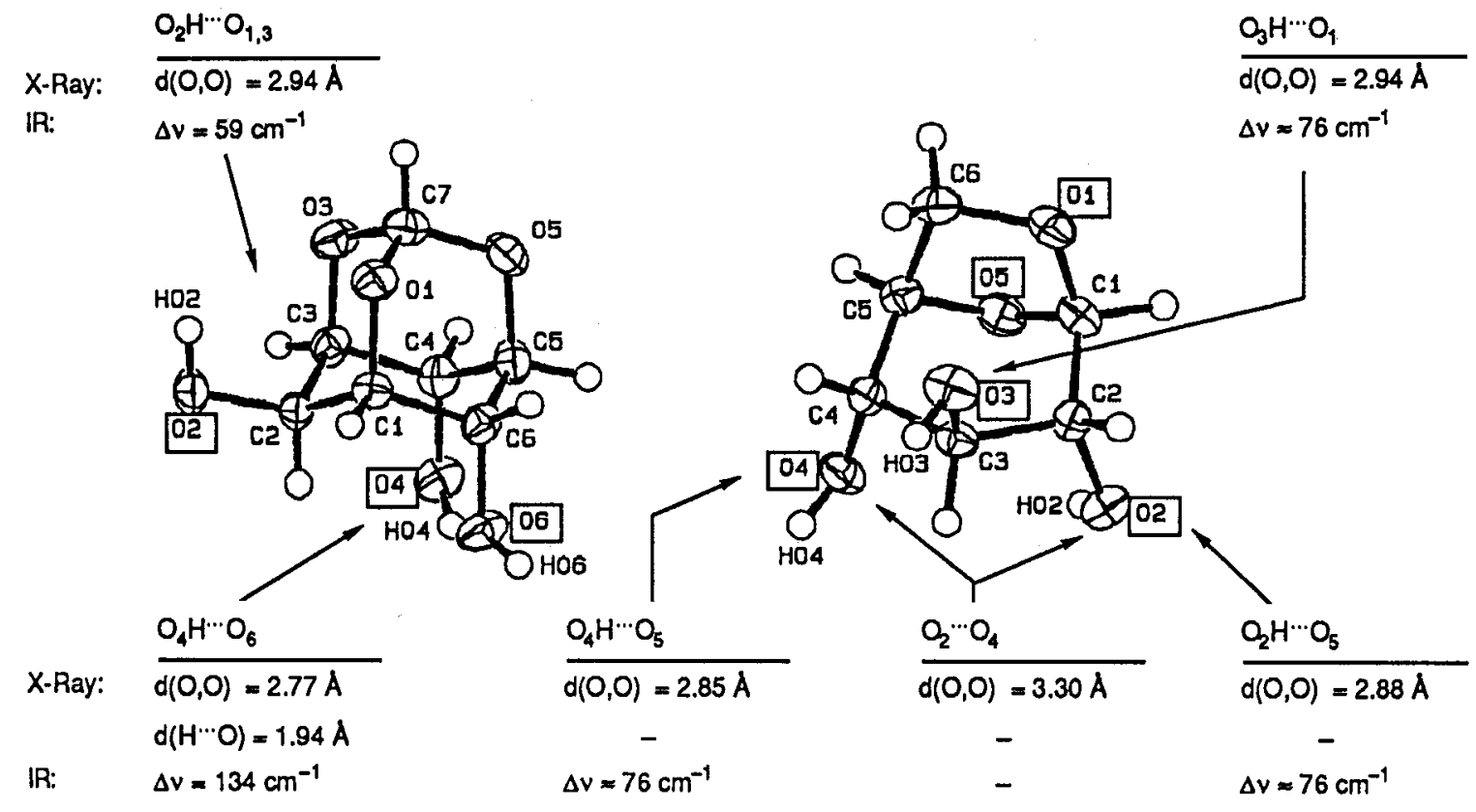


Glycosidation of the myo-inositol derivative 58, possessing a 1,3-diaxial diol unit indeed yielded $90 \%$ of the two B-Dconfigurated monoglycosides 59 and 60, derived from glycosidation of the enantiotopic axial hydroxy groups (Scheme 10. The equatorial hydroxy group is not glycosylated (ref. 33). Glycosylation by the 2-deoxy-1-azi-glucose 9 shows no stereoselectivity (ref. 34). These results agree with expectation. Glycosidation of 1,6-anhydro-glucose (61) by 1 gave markedly different results (Scheme 17). Yields are sensibly lower. The HO-C(3) group is practically not reactive. There is not much regiodifference for HO-C(2) $(\rightarrow 62$ and 63) and $\mathrm{HO}-\mathrm{C}(4)(\rightarrow 64$ and 65$)$. There is a low degree of stereoselectivity. Hence, 58, but not 61 should possess an intramolecular H-bond. Indeed, X-ray analysis of 58 (ref. 33) shows a relatively strong intramolecular $\mathrm{H}$-bond (Scheme 18), which is also present in solution, as evidenced by a shift of $134 \mathrm{~cm}^{-1}$ for the $\mathbb{R}$ band corresponding to the axial hydroxy groups. A smaller band shift for the equatorial hydroxy group indicates that it forms a weak H-bond, lowering its reactivity. No intramolecular H-bond is found for 61 in the solid state (ref. 35), the distance between the two cis-hydroxy groups being too long ('reverse reflex effect"; ref. 36). Its IR spectrum shows only one OH-band shift of $76 \mathrm{~cm}^{-1}$, indicating that the three $\mathrm{OH}$ groups are involved in OH-bonds. While $\mathrm{HO}-\mathrm{C}(2)$ and $\mathrm{HO}-\mathrm{C}(4)$ compete for $\mathrm{O}(5)$ as $\mathrm{H}$-bond acceptor, $\mathrm{HO}-\mathrm{C}(3)$ may always form a $\mathrm{H}$-bond with $\mathrm{O}(1)$, and this could explain its deactivation.

Scheme 19. Dependence of the glycosidation on the concentration of the acceptor
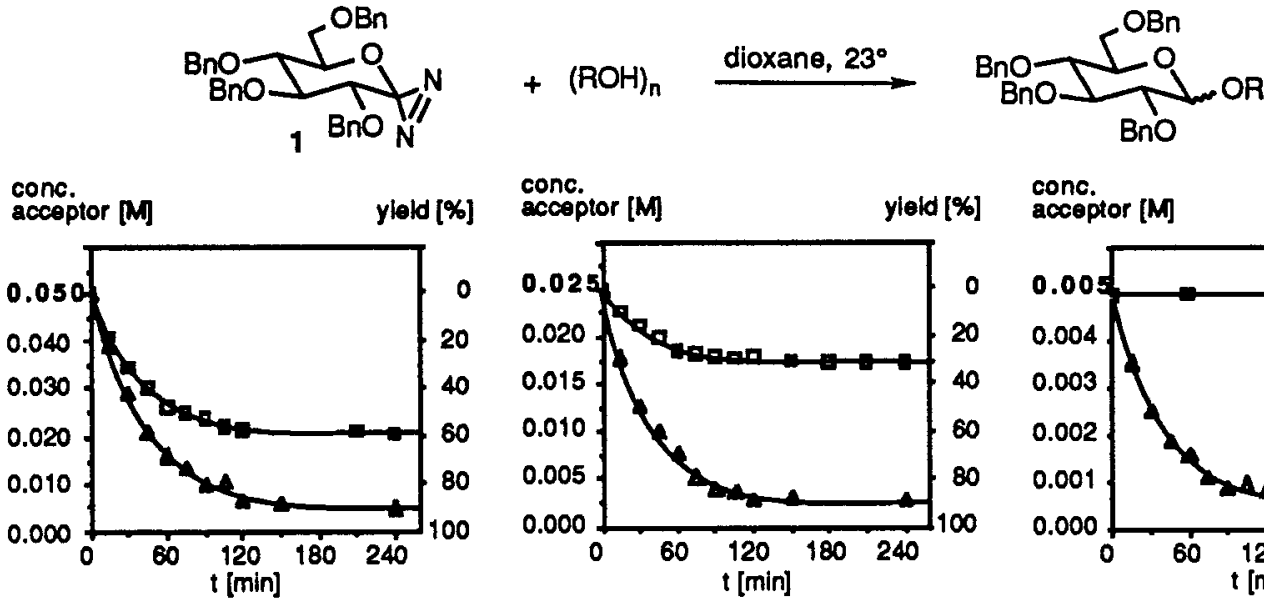

cone.

acceptor [M] yield [\%]

$\Delta$<smiles>OC1C2OC3OC(O2)C(O)C1C3O</smiles><smiles>OC1C2OC3C(O)C1C3O2</smiles>

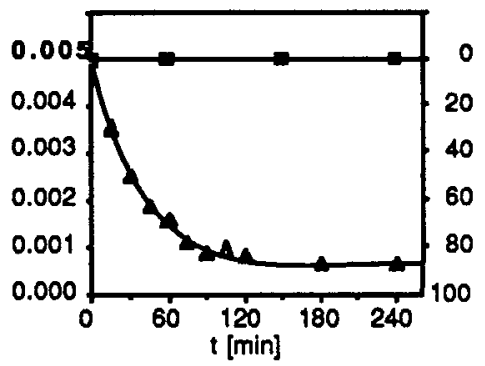

Does the glycosylation of 61 reflect the reactivity of the monomer, or does 61 only react because the acidity of HO$\mathrm{C}(2)$ and of HO-C(4) is enhanced by intermolecular H-bonds? This question is answered by the dependence of glycoside formation upon the concentration of the triols 58 and 61 (Scheme 19). Increasing dilution affects the yields of glycosides derived from the triols 58 and 60 in a very different way; no influence is visible for the glycosidation of 58, while the yields obtained from 61 are strongly affected. Lowering the concentration by one order of magnitude suppresses the formation of glycosides completely. Evidently, dimeric or oligomeric 61 reacts with the carbene.

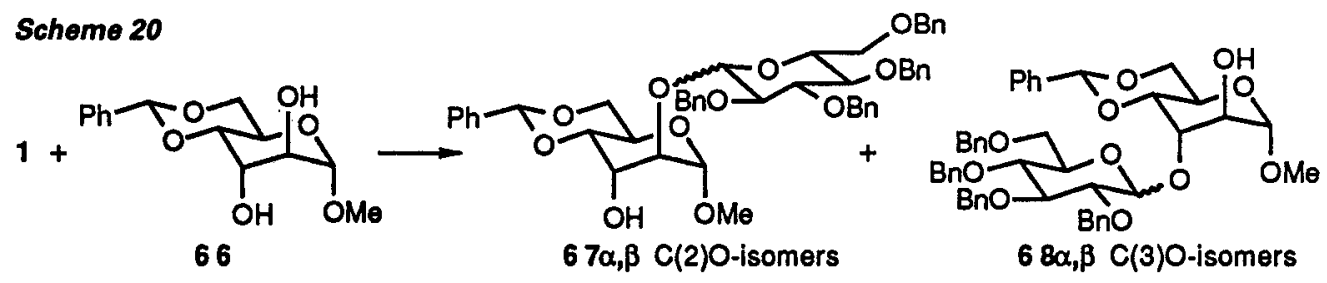

\begin{tabular}{|lcccc|}
\hline Reaction conditions & Total yield & Regioselectivity & \multicolumn{2}{c|}{ Diastereoselectivity } \\
$(1.1$ cq. Diazirine $)$ & {$[\%]$} & $67 \alpha, \beta: 68 \alpha, \beta$ & $67 \alpha: 67 \beta$ & $68 \alpha: 68 \beta$ \\
\hline $\mathrm{ClCH}_{2} \mathrm{CH}_{2} \mathrm{Cl}, 24^{\circ}$ & 71 & $93: 7$ & $35: 65$ & $51: 49$ \\
$\mathrm{CH}_{2} \mathrm{Cl}_{2}, 24^{\circ}$ & 52 & $82: 18$ & $41: 59$ & $73: 27$ \\
dioxane, $24^{\circ}$ & 57 & $87: 13$ & $18: 82$ & $18: 82$ \\
THF, $-80^{\circ}$, hv & 50 & $71: 29$ & $5: 95$ & $17: 83$ \\
\hline
\end{tabular}


H-bond donation by an alcoholic hydroxy group lowers its kinetic acidity. Such a group should be less reactive towards a glycosylidene carbene. However, as one may consider such a hydroxy group to be partially deprotonated, it ought to be more reactive towards a glycosyl cation, i.e. in a Koenigs-Knorr-type glycosylation. A situation as it is realised in the altro-diol 66 should thus lead to a (complementary) regioselective glycosidation by either method (ref. 37). This is shown in Scheme 20 for the reaction of 66 with 1. Two regioisomeric pairs of anomers result. Regioselectivity is better than 9:1 and favours glycosidation at $C(2)$, as expected. Diastereoselectivity is unsatisfactory. Yield and selectivity depend upon the reaction conditions, particularly the solvent. Regioselectivity was highest when $\mathrm{ClCH}_{2} \mathrm{CH}_{2} \mathrm{Cl}$ is used, and diastereoselectivity was best in THF or dioxane. There is a consistent preference for $67 \beta$. With the exception of $\mathrm{CH}_{2} \mathrm{Cl}_{2}$, all solvents also favour formation of $68 \beta$. Concerning the ease of predicting $\mathrm{H}$-bonds, one may note that X-ray analysis of 66 only shows intermolecular H-bonds, while IR spectra evidence a strong intramolecular H-bond. Osmometry indicates that 66 is monomeric, and dilution experiments that it reacts as the monomer!

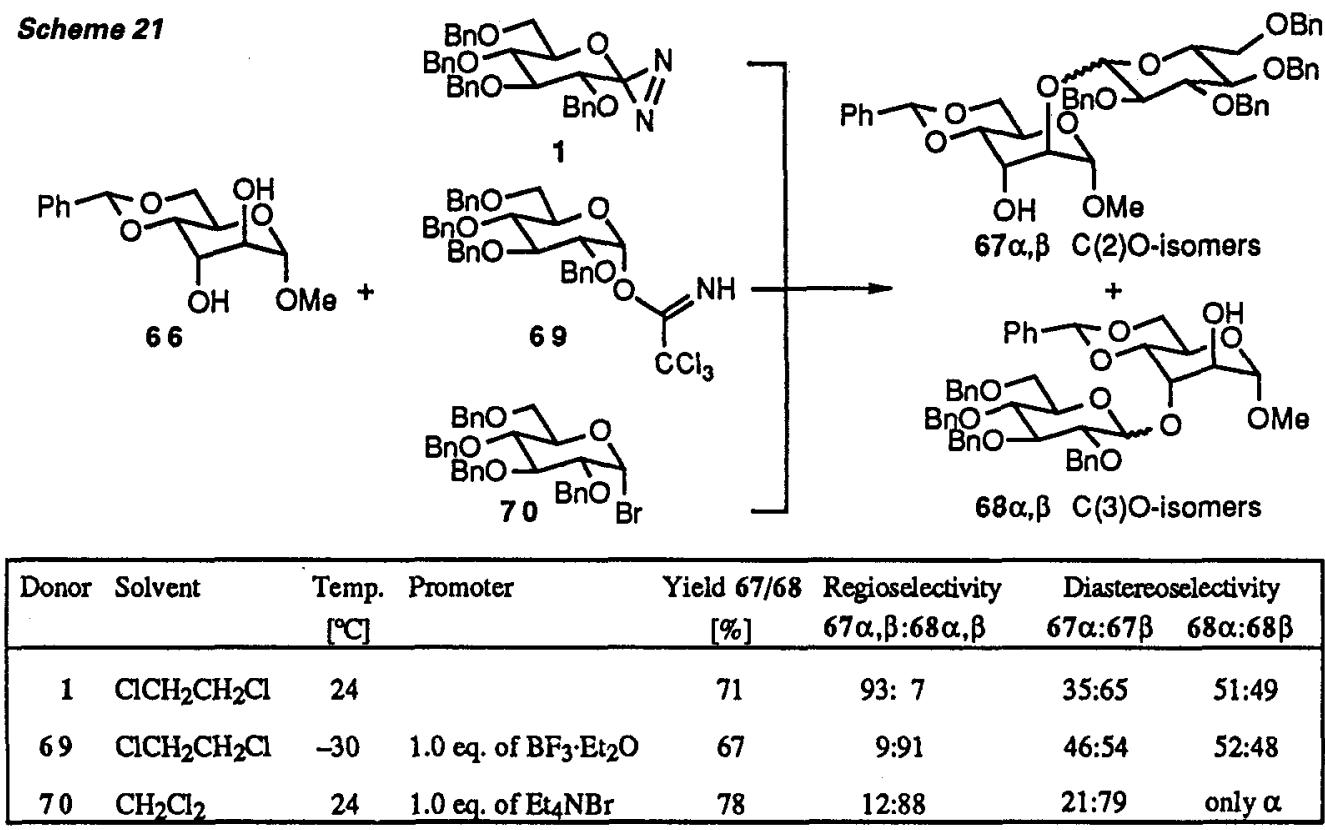

\section{Scheme 22}

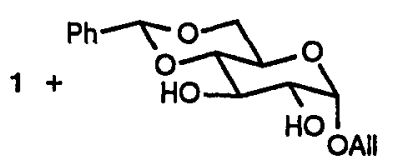

71

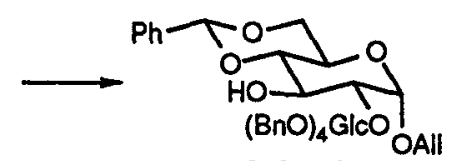

$73 \alpha, \beta \mathrm{C}(2)$-isomers

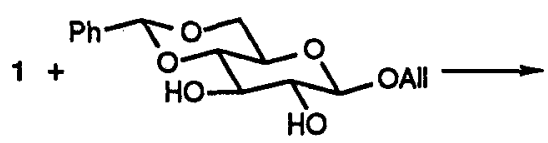

72

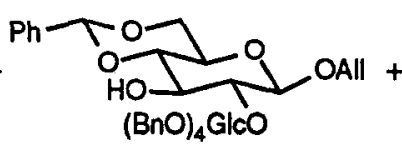

$75 \alpha, \beta C(2)$-isomers

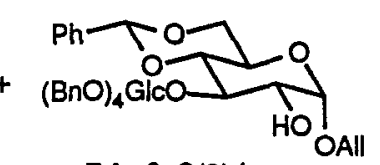

$74 \alpha, \beta \quad C(3)$-isomers

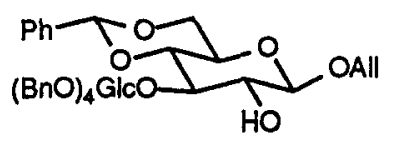

$76 \alpha, \beta \quad C(3)$-isomers

\begin{tabular}{|llcccccc|}
\hline Diol & Solvent & Diol: 1 & $\begin{array}{c}\text { Temp. } \\
{\left[{ }^{\circ} \mathrm{C}\right]}\end{array}$ & $\begin{array}{c}\text { Yield } \\
{[\%]}\end{array}$ & $\begin{array}{c}\text { Regioselectivity } \\
\mathrm{C}(2) \mathrm{C}: \mathrm{C}(3) \mathrm{O}\end{array}$ & \multicolumn{2}{c|}{$\begin{array}{c}\text { Diastereoselectivity } \\
\alpha: \beta \mathrm{C}(2) \mathrm{\alpha} \alpha: \beta \mathrm{C}(3) \mathrm{O}\end{array}$} \\
\hline $\mathbf{7 1}$ & Toluene & $1.3: 1.0$ & 50 & 69 & $37: 63$ & $37: 63$ & $34: 66$ \\
$\mathbf{7 1}$ & Dioxane & $1.3: 1.0$ & 22 & $\mathbf{7 2}$ & $44: 56$ & $39: 61$ & $36: 64$ \\
$\mathbf{7 1}$ & $\mathrm{ClCH}_{2} \mathrm{CH}_{2} \mathrm{Cl}$ & $1.0: 1.3$ & 22 & 89 & $46: 54$ & $46: 54$ & $38: 61$ \\
& & & & & & & \\
$\mathbf{7 2}$ & Toluene & $1.3: 1.0$ & 70 & 70 & $47: 53$ & $40: 60$ & $44: 56$ \\
$\mathbf{7 2}$ & Dioxane & $1.3: 1.0$ & 22 & 69 & $46: 54$ & $32: 68$ & $38: 62$ \\
$\mathbf{7 2}$ & $\mathrm{ClCH}_{2} \mathrm{CH}_{2} \mathrm{Cl}$ & $1.0: 1.3$ & 22 & 94 & $52: 48$ & $53: 47$ & $35: 65$ \\
\hline
\end{tabular}

To demonstrate the complementarity between the carbene-mediated and the Koenigs-Knorr-type glycosylation, we exposed 66 to the conditions of the Schmidt- and of the Lemieux-glycosylation (ref. 1a and 38). Indeed, both donors, 69 and 70, gave predominantly 68, derived from glycosylation of HO-C(3) (Scheme 21). Moreover, the halide-exchange method was highly stereoselective, suggesting that it may be very well suited for the regioselective glycosylation of acceptors possessing such a H-donating hydroxy group. 
Scheme 23

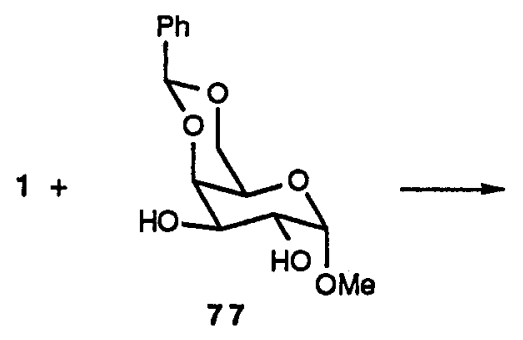

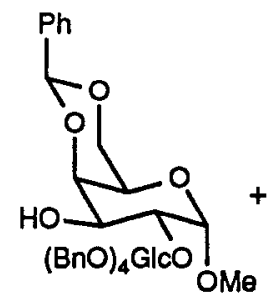

$79 \alpha, \beta \quad \mathrm{C}(2)$-Isomers

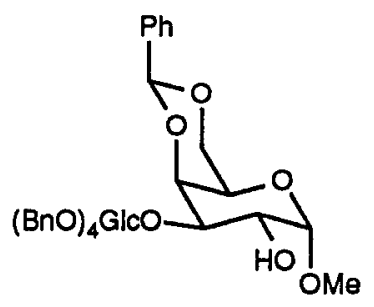

$80 \alpha, \beta C(3)$-isomers
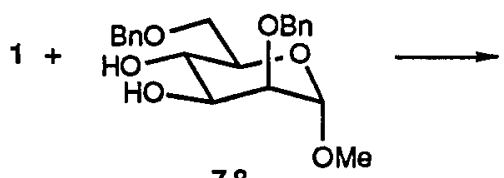

\begin{tabular}{|c|c|c|c|c|c|c|c|}
\hline Diol & Solvent & Diol : 1 & Temp. $\left[{ }^{\circ} \mathrm{C}\right]$ & Yield [\%] & Regioselectivity & \multicolumn{2}{|c|}{ Diastereoselectivity } \\
\hline & & & & & $79 \alpha, \beta: 80 \alpha, \beta$ & $79 \alpha: 79 \beta$ & $80 \alpha: 80 \beta$ \\
\hline 77 & Toluene & $1.3: 1.0$ & 70 & 70 & $50: 50$ & $35: 65$ & $46: 54$ \\
\hline 77 & Dioxane & $1.3: 1.0$ & 23 & 75.5 & $50: 50$ & $39: 61$ & $59: 41$ \\
\hline 77 & $\mathrm{ClCH}_{2} \mathrm{CH}_{2} \mathrm{Cl}$ & $1.0: 1.3$ & 23 & 80 & $50: 50$ & $44: 56$ & $52: 48$ \\
\hline & & & & & $81 \alpha, \beta: 82 \alpha, \beta$ & $81 \alpha: 81 \beta$ & $82 \alpha: 82 \beta$ \\
\hline 78 & Toluene & $1.3: 1.0$ & 70 & 75 & $54: 46$ & $64: 36$ & $48: 52$ \\
\hline 78 & Dioxane & $1.3: 1.0$ & 24 & 71 & $50: 50$ & $59: 41$ & $52: 48$ \\
\hline 78 & Dioxane & $1.0: 1.3$ & 24 & 80 & $49: 51$ & $61: 39$ & $49: 51$ \\
\hline
\end{tabular}

\section{Scheme 24}
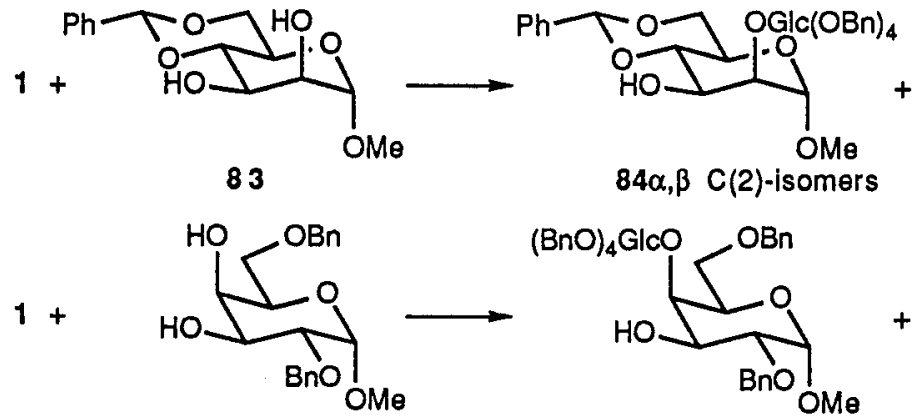

86

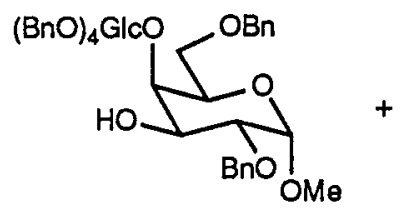

$87 \alpha, \beta \quad C(4)$-isomers

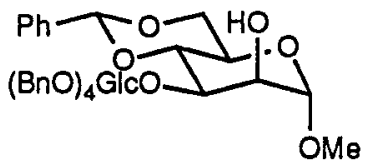

$85 \alpha, \beta C(3)$-isomers<smiles>COC(OCc1ccccc1)C(OCc1ccccc1)C(O)C(OCc1ccccc1)C(C)(C)Cc1ccccc1</smiles>

$88 \alpha, \beta C(3)$-isomers

\begin{tabular}{|llcccccc|}
\hline Diol & Solvent & Diol : 1 & Temp. $\left[{ }^{\circ} \mathrm{C}\right]$ & Yield $[\%]$ & Regioselectivity & \multicolumn{2}{c|}{ Diastereoselectivity } \\
\hline & & & & & $\mathbf{8 4 \alpha , \beta : 8 5 \alpha , \beta}$ & $\mathbf{8 4 \alpha : 8 4 \beta}$ & $\mathbf{8 5} \alpha: 85 \beta$ \\
$\mathbf{8 3}$ & Toluene & $1.3: 1.0$ & 70 & 89 & $24: 76$ & $38: 62$ & $40: 60$ \\
$\mathbf{8 3}$ & Dioxane & $1.3: 1.0$ & 23 & 83 & $29: 71$ & $29: 71$ & $39: 61$ \\
$\mathbf{8 3}$ & ClCH$_{2} \mathrm{CH}_{2} \mathrm{Cl}$ & $1.0: 1.3$ & 23 & 96 & $39: 61$ & $48: 52$ & $38: 62$ \\
& & & & & $\mathbf{8 7 \alpha , \beta : 8 8 \alpha , \beta}$ & $\mathbf{8 7 \alpha : 8 7 \beta}$ & $\mathbf{8 8} \alpha: 88 \beta$ \\
$\mathbf{8 6}$ & Toluene & $1.3: 1.0$ & 70 & 68 & $14: 86$ & $47: 53$ & $54: 46$ \\
$\mathbf{8 6}$ & Dioxane & $1.3: 1.0$ & 24 & 67 & $26: 74$ & $39: 61$ & $51: 49$ \\
$\mathbf{8 6}$ & Dioxane & $1.0: 1.3$ & 24 & 74 & $25: 75$ & $39: 61$ & $47: 53$ \\
\hline
\end{tabular}

To further study the effect of H-bonds upon regioselectivity, we examined the glycosidation of pyranosides possessing 1,2-cis axial-equatorial, and 1,2-trans diequatorial diol units (ref. 39). As shown in Scheme 22, the trans-diequatorial gluco-diols 71 and 72 are monoglycosylated in fair yields (relative to 1 ). A small excess of the diazirine boosts the yield (referring to the diols) to $90 \%$, but there is hardly any regio- and little stereoselectivity. The neighbourhood of the anomeric centre has a small influence on yield and selectivity, as may be gathered by comparing these results to those presented in Scheme 23. Both the 1,2-trans diequatorial galacto-diol 77 and the analogous manno-diol 78 react with very poor regio- and poor stereoselectivity. The situation is more favourable in 1,2-cis diols (Scheme 24). The 
equatorial hydroxy group of the manno-diol 83 is more reactive, and yields of 85 are quite good, with a slight preference for the $\beta$-D-anomer. Similariy, the equatorial hydroxy group of the galacto-diol 86 is preferentially glycosylated, but again with a low degree of stereoselectivity.

The preferential glycosylation of the equatorial hydroxy group of 86 is surprising. Similarly as for the altro-diol 66, one would expect the results of the carbene-mediated and of the Koenigs-Knorr type glycosylation of 86 to be complementary to each other. Thus, the nucleophilicity of the axial hydroxy groups of 83 and of 86 should be enhanced, if their weak reactivity towards a carbene is due to a lowered kinetic acidity (H-bond to the ring-oxygen). It is, however, the equatorial hydroxy group of galacto 3,4-diols which reacts preferentially in a Koenigs-Knorr-glycosidation, unless highly insoluble promoters are used (ref. 7b, 7f, 7j, 7l-q, 7v, 7x, 7y).

\section{Scheme 25}

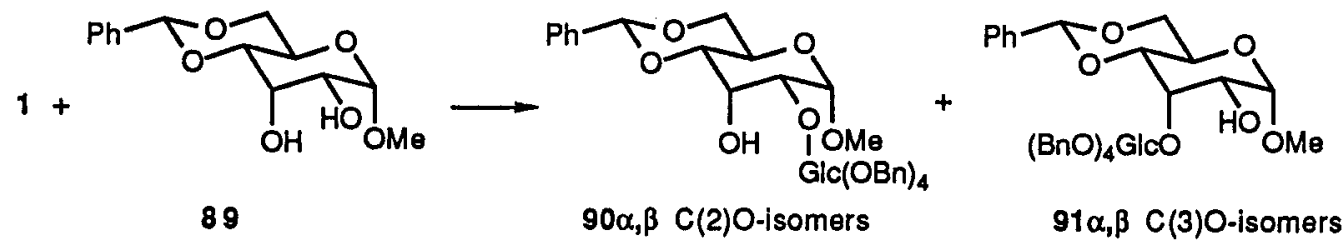

\begin{tabular}{|c|c|c|c|c|c|}
\hline \multirow[t]{2}{*}{ Solvent } & \multirow{2}{*}{$\begin{array}{l}\text { Temp. } \\
{\left[{ }^{\circ} \mathrm{C}\right]}\end{array}$} & \multirow{2}{*}{$\begin{array}{l}\text { Yicld } \\
{[\%]}\end{array}$} & \multirow{2}{*}{$\begin{array}{l}\text { Regioselectivity } \\
90 \alpha, \beta: 91 \alpha, \beta\end{array}$} & \multicolumn{2}{|c|}{ Diastereoselectivity } \\
\hline & & & & $90 \alpha: 90 \beta$ & $91 \alpha: 91 \beta$ \\
\hline Toluene & 70 & 79 & $20: 80$ & $32: 68$ & $72: 28$ \\
\hline Dioxane & 24 & 81 & $28: 72$ & $39: 61$ & $89: 11$ \\
\hline THF & 24 & 75 & $40: 60$ & $25: 75$ & $66: 34$ \\
\hline THF & -85 & 79 & $72: 28$ & $10: 90$ & $67: 33$ \\
\hline
\end{tabular}

\section{Scheme 26}

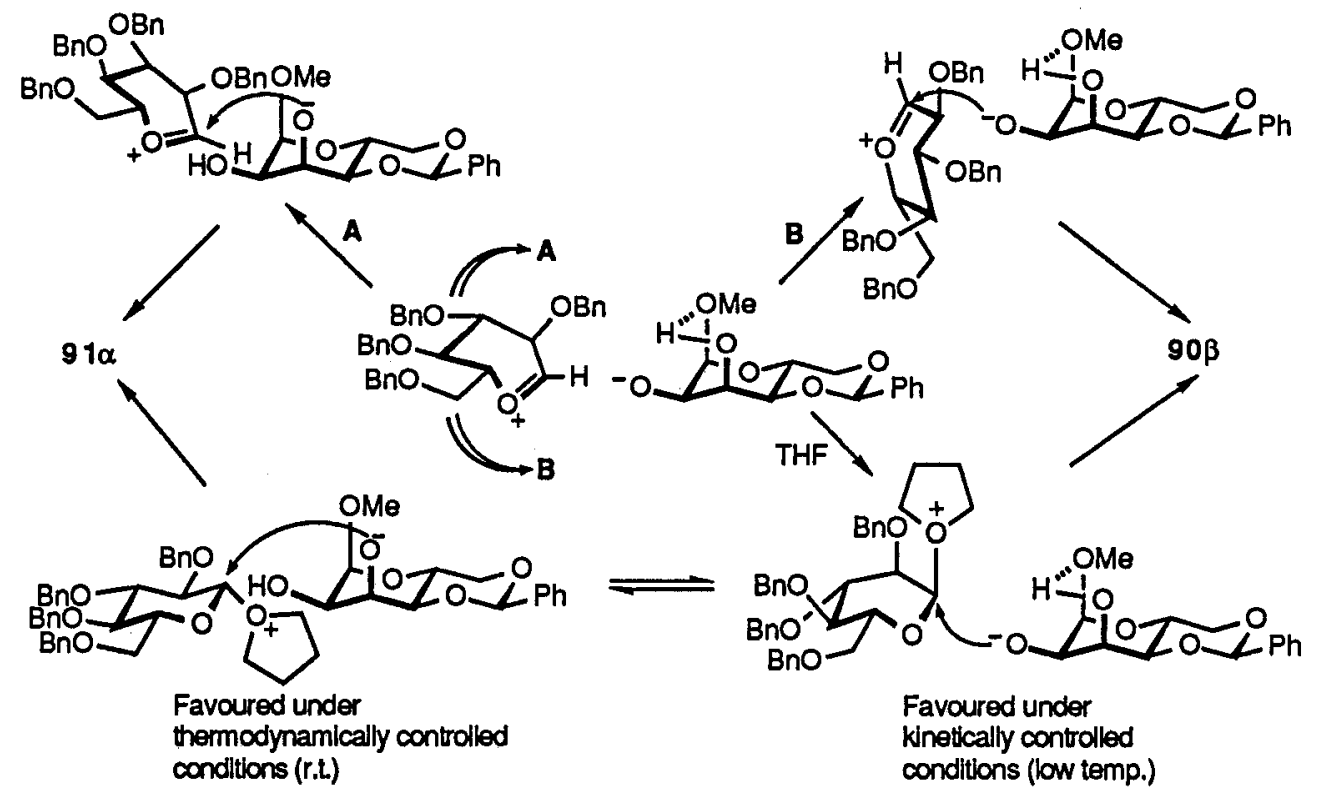

The behaviour of 83 and 86 towards carbenes may find its explanation in the light of the results with the allo-diol 89 (Scheme 25). X-ray analysis, ${ }^{1} \mathrm{H}-\mathrm{NMR}$, and $\mathrm{IR}$ spectra demonstrate a H-bond between the axial HO-C(3) and the methoxy group. The kinetic acidity of HO-C(3) should thus be lowered, and one may expect glycosidation at HO$\mathrm{C}(2)$. It is, however, $\mathrm{HO}-\mathrm{C}(3)$ which is preferentially glycosylated, except in THF and at a low temperature. Also, one notes a different anomeric selectivity for the formation of 90 and 91 . To rationalise these results, one has to remember that protonation of the carbene by the kinetically most acidic hydroxy group takes place in the $\sigma$-plane of the carbenic centre, while the ensuing oxycarbenium ion is attacked in the $\pi$-plane. The two hydroxy groups of 89 are located in two different planes. If $\mathrm{HO}-\mathrm{C}(2)$ protonates the carbene in the $\sigma$-plane, then $\mathrm{HO}-\mathrm{C}(3)$ is favourably placed in the $\pi$ plane of the oxycarbenium ion. All that is required is a (facile) proton shift to ${ }^{-0} \mathrm{C}(3)$, then HO-C(3) attacks. We can explain the regio- and the stereoselectivity by assuming a specific orientation of carbene and diol, which leads to the ion pair, depicted in Scheme 26. If proton transfer from HO-C(3) to -O-C(2) is accompanied by a relative movement of the carbocation according to $A$, one obtains $91 \alpha$. A movement according to $B$ leads to attack by $-O-C(2)$, and to $90 \beta$. The process $B$ implies a (partial) dissociation of the ion pair. Hence, the preferred pathway under all conditions, except in 
THF at low temperature, is formation of $91 \alpha$. For the reactions in THF, solvation of the oxycarbenium ion from the axial side is kinetically preferred, as discussed above. Substitution with inversion of the configuration at the anomeric centre requires attack by $-\mathrm{O}-\mathrm{C}(2)$, and leads to $90 \beta$, the major product under these conditions. At higher temperatures, the tetrahydrofuranylium ions equilibrate, and a competing inverting substitution of the presumably more reactive $\beta$-Danomer by $-0-C$ (3) takes place from the $\alpha$-side leading to $91 \alpha$ (ref. 40).

\section{Scheme 27}

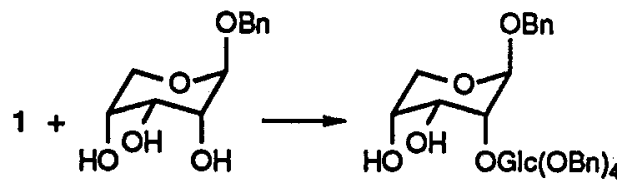

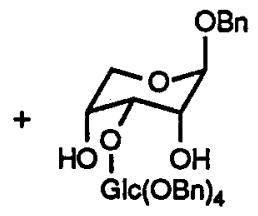

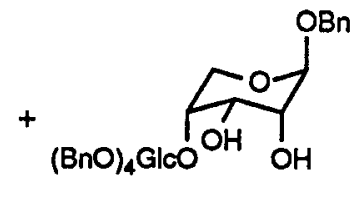

92 $93 \alpha, \beta$ C(2)O-isomers

$94 \alpha, \beta C(3)$-isomers

$95 \alpha, \beta \quad C(3) O$-isomers

\begin{tabular}{|llcccccc|}
\hline Solvent & $\begin{array}{l}\text { Conc. } \\
\end{array}\left[\begin{array}{c}\text { Temp. } \\
{[\mathrm{M}]}\end{array}\right.$ & {$\left[{ }^{\circ}\right]$} & $\begin{array}{c}\text { Total yield } \\
{[\%]}\end{array}$ & $\begin{array}{c}\text { Regioselectivity } \\
93 \alpha, \beta: 94 \alpha, \beta: 95 \alpha, \beta\end{array}$ & \multicolumn{3}{c|}{ Diastereoselectivity } \\
\hline dioxane & 0.05 & 27 & 69 & $30: 40: 30$ & $33: 67$ & $75: 25$ & $60: 40$ \\
$\mathrm{CH}_{2} \mathrm{Cl}_{2}$ & 0.05 & 22 & 85 & $17: 59: 24$ & $41: 59$ & $80: 20$ & $63: 37$ \\
$\mathrm{CH}_{2} \mathrm{Cl}_{2}$ & 0.05 & -78 & 66 & $14: 57: 29$ & $57: 43$ & $75: 25$ & $72: 28$ \\
$\mathrm{CH}_{2} \mathrm{Cl}_{2}$ & 0.005 & -78 & 63 & $5: 81: 14$ & $40: 60$ & $77: 23$ & $64: 36$ \\
\hline
\end{tabular}

\section{Scheme 28}

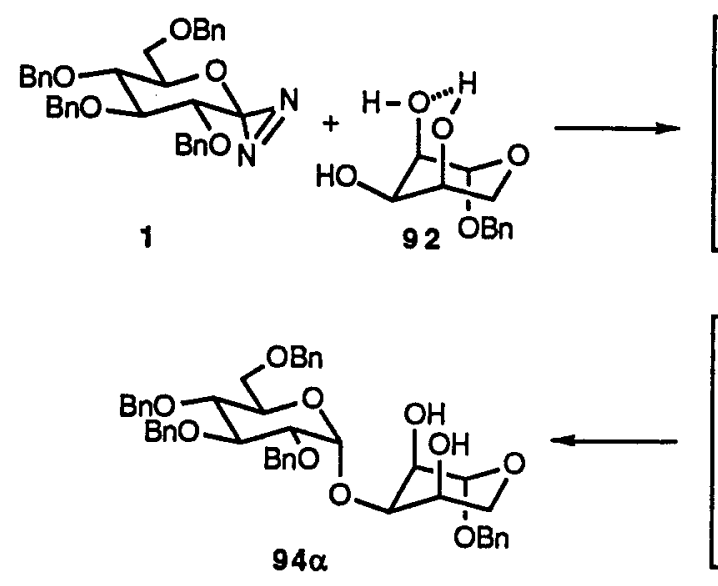

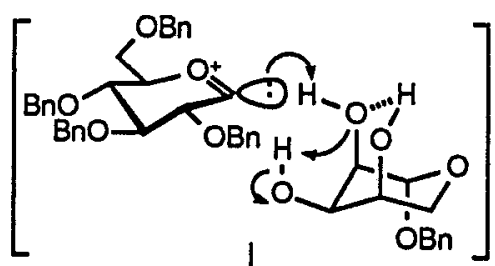

Glycosidation of the ribo-triol 92 exemplifies a situation which is complementary to the one illustrated by the allo-diol 89 (Scheme 27). Here, protonation of the carbene by one of the axial hydroxy groups - the one acting as a H-bond acceptor in the hydrogen bonded 1,3-diaxial diol unit - should be followed by hydrogen transfer from the equatorial hydroxy group and by glycosidation at ${ }^{-} O-C(3)$. Indeed, the major regioisomers are $94 \alpha$ and $94 \beta$. Among the minor regioisomers, there is a slight preference for $93 \beta$, and for $95 \alpha$. Dilution experiments suggest that the major isomer is formed from the monomeric, and the minor products from oligomeric triol. A plausible transition state is formulated in Scheme 28 (ref. 40).

One may now attempt to predict the regioselectivity of the glycosidation of the triol 96 (Scheme 29). We expect a $\mathrm{H}$-bond between $\mathrm{HO}-\mathrm{C}(3)$ and the methoxy group and a low kinetic acidity for $\mathrm{HO}-\mathrm{C}(3)$. The most acidic hydroxy group should be $\mathrm{HO}-\mathrm{C}(2)$, as it is vicinal to the acetal centre, and trans-axial to two $\mathrm{C}-\mathrm{O}$ bonds. The carbene derived from 1 should be preferentially protonated by this group. As there is no hydroxy group cis to $-0-C(2)$ and favourably located to attack the oxycarbenium ion in the $\pi$-plane, we have to assume dissociation of the ion pair, and attack by ${ }^{-} \mathrm{O}-$ $\mathrm{C}(2)$. Next, we expect protonation by HO-C(4). Attack in the $\pi$-plane of the oxycarbenium ion is presumably only possible by $\mathrm{HO}-\mathrm{C}(3)$ as the $\mathrm{H}$-bond from $\mathrm{HO}-\mathrm{C}(3)$ to the methoxy group points away from the $-\mathrm{O}-\mathrm{C}(4)$. Intramolecular proton transfer to $-\mathrm{O}-\mathrm{C}(4)$ may therefore not be rapid enough. Still, $\mathrm{HO}-\mathrm{C}(3)$ should be nucleophilic enough to ensure its rapid glycosidation by the glycosyl cation. The ratio of regioisomers corresponds qualitatively to this prediction. There is little stereoselectivity in the formation of the major regioisomers 97 (dissociation of the ionpair!), except at low temperatures in THF, where $97 \beta$ dominates, as expected (ref. 40 ). 


\section{Scheme 29}

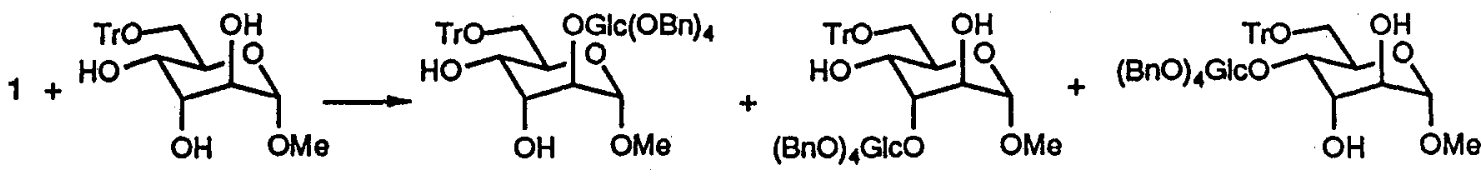

96

$97 \alpha, \beta \mathrm{C}(2) \mathrm{O}$-isomers

$98 \alpha, \beta \quad C(3) O-i s o m e r s$

$99 \alpha, \beta \quad C(3) O$-isomers

\begin{tabular}{|lcccccc|}
\hline Solvent & Temp. & Total Yield & Regioselcctivity & \multicolumn{3}{c|}{ Diastereoscloctivity } \\
& {$\left[{ }^{\circ} \mathrm{C}\right]$} & {$[\%]$} & $97 \alpha, \beta: 98 \alpha, \beta: 99 \alpha, \beta$ & $97 \alpha: 97 \beta$ & $98 \alpha: 98 \beta$ & $99 \alpha: 99 \beta$ \\
\hline $\mathrm{CH}_{2} \mathrm{Cl}_{2}$ & 24 & 53 & $57: 30: 13$ & $49: 51$ & $46: 54$ & $64: 36$ \\
dioxanc & 24 & 49 & $50: 37: 13$ & $62: 38$ & $36: 64$ & $54: 46$ \\
THF & 24 & 54 & $47: 39: 13$ & $49: 51$ & $28: 72$ & $50: 50$ \\
THF & -80 & 50 & $43: 52: 5$ & $9: 91$ & $13: 87$ & $84: 16$ \\
\hline
\end{tabular}

A particularly strong intramolecular H-bond (IR: $\Delta v=253 \mathrm{~cm}^{-1}$ ) is formed between $\mathrm{HO}-\mathrm{C}(3)$ and one of the carbonyl groups of the N-phthalimido substituent in 100 (Scheme 30). There is also good evidence for a weaker H-bond between HO-C(4) and $O-C(3)$. Reaction of 100 with 1 gave 101 regiospecifically and in good yields. Stereoselectivity is also high, and favours $101 \alpha$. Initial protonation by HO-C(4) is evidenced by the finding that the 4,6-0-benzylidene-analogue of 100 is not glycosylated by 1 . In 100, as in 96, the glycosyl cation is attacked by the neighbouring hydroxy group, as the geometry of the $\mathrm{H}$-bond is unfavourable for a hydrogen transfer to the initially formed $-O-C(4)$. The conformation of the phthalimido group in the $\beta-D$ anomer 102 is different from the one in 101; yields (60\%; 30\% recovered 102), regio-, and stereoselectivity of the glycosidation of 102 are much lower.
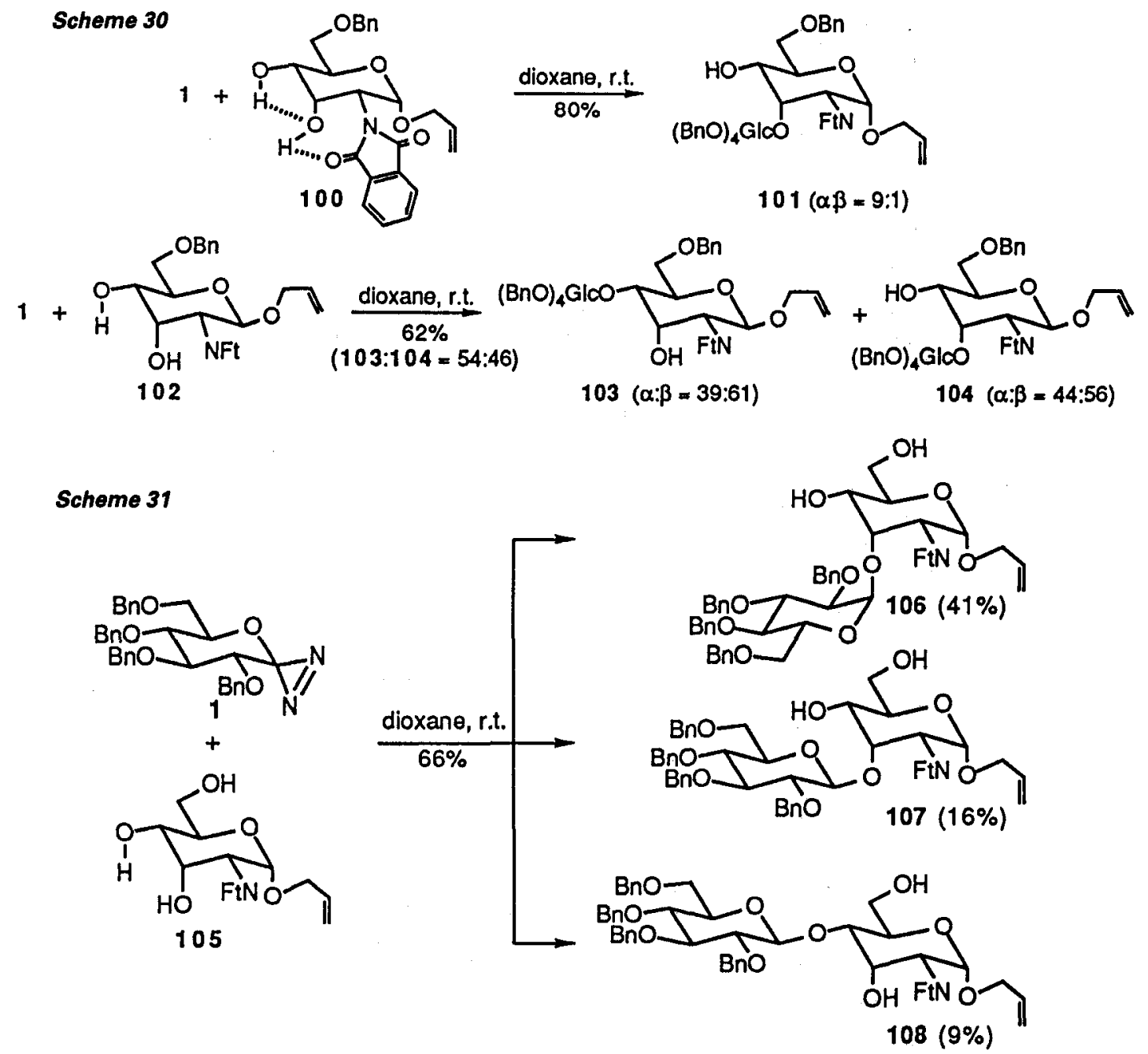
The triol 105 (Scheme 31) reacts again with a high degree of regioselectivity, yielding mostly 106 and its anomer 107; no products of glycosidation of the primary hydroxy group are found. This is not trivial. The glycosyl cation, formed by deprotonation of $\mathrm{HO}-\mathrm{C}(4)$ could, a priori, be attacked by $\mathrm{HO}-\mathrm{C}(3)$ or by the primary hydroxy group. The

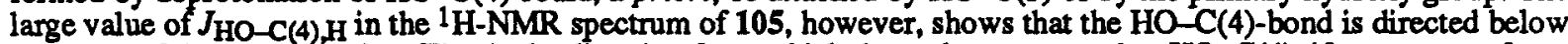
the plane of the pyranose ring. That is the direction from which the carbene approaches HO-C(4), if proton transfer to the carbene is approximately linear. Thus, the glycosyl cation will also be located below the pyranose ring plane, away from $\mathrm{HO}-\mathrm{C}(6)$. One may conclude that not only the kinetic acidity of a hydroxy group and its geometric relation to neighbouring hydroxy groups, but also the population of its rotamers may be reflected in the regioselectivity of the glycosidation. Evidently, the expected higher nucleophilicity of HO-C(3) (strong H-bond!) is not to be neglected (ref. 41).

\section{Scheme 32}

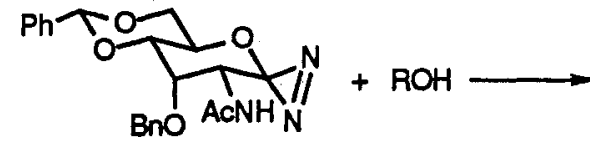

11

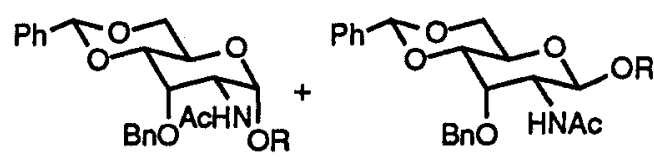

$109 \alpha, \beta \quad \mathrm{R}=\mathrm{CH}\left(\mathrm{CF}_{3}\right)_{2}$

$110 \alpha, \beta \quad \mathrm{R}=\mathrm{CHMe}_{2}$

\begin{tabular}{|lclll|}
\hline ROH & $\mathrm{pK}_{\mathrm{HA}}$ & Conditions & Yicld [\%] & $\alpha: \beta$ \\
\hline$\left(\mathrm{CF}_{3}\right)_{2} \mathrm{CHOH}$ & 9.3 & $\mathrm{CH}_{2} \mathrm{Cl}_{2},-84^{\circ} \mathrm{hv}$ & $109: 88$ & $52: 48$ \\
& & $\mathrm{CH}_{2} \mathrm{Cl}_{2}, 41^{\circ}$ & $109: 85$ & $76: 24$ \\
& & & & \\
$\left(\mathrm{CH}_{3}\right)_{2} \mathrm{CHOH}$ & 17.1 & $\mathrm{CH}_{2} \mathrm{Cl}_{2},-84^{\circ} \mathrm{hv}$ & $110: 72$ & $78: 22$ \\
& & $\mathrm{CH}_{2} \mathrm{Cl}_{2}, 41^{\circ}$ & $110: 12$ & only $\alpha$ \\
\hline
\end{tabular}

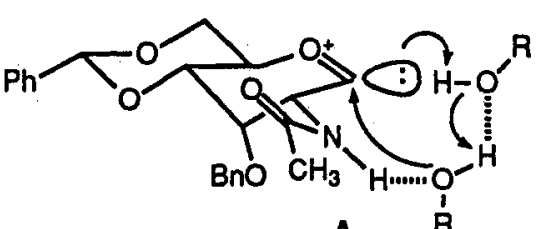

A

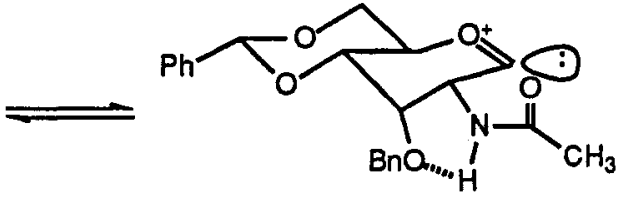

$\mathbf{B}$

Yet another effect of hydrogen bonding became apparent, when we examined the reaction of the AllNAc-derived diazirine 11 with alcohols (Scheme 32). At $41^{\circ}$, the strongly acidic hexafluoro-2-propanol yielded over $80 \%$ of a mixture of $109 \alpha, \beta$, the $\alpha$-D-anomer dominating to an extent of 76:24! Stereoselectivity almost disappears at low temperature. A similar result is observed for the reaction of 11 with 2-propanol, with the difference that the stereoselectivity at low temperatures is higher for this weakly acidic alcohol. Under thermal conditions, $110 \beta$ is only formed in low yields (ref. 42 ).

\section{Scheme 33}<smiles>OC(O)C1COC2N=NC1C(c1ccccc1)O2</smiles>

11

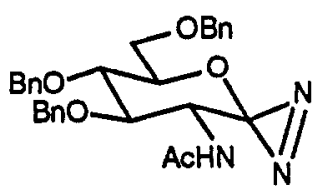

111

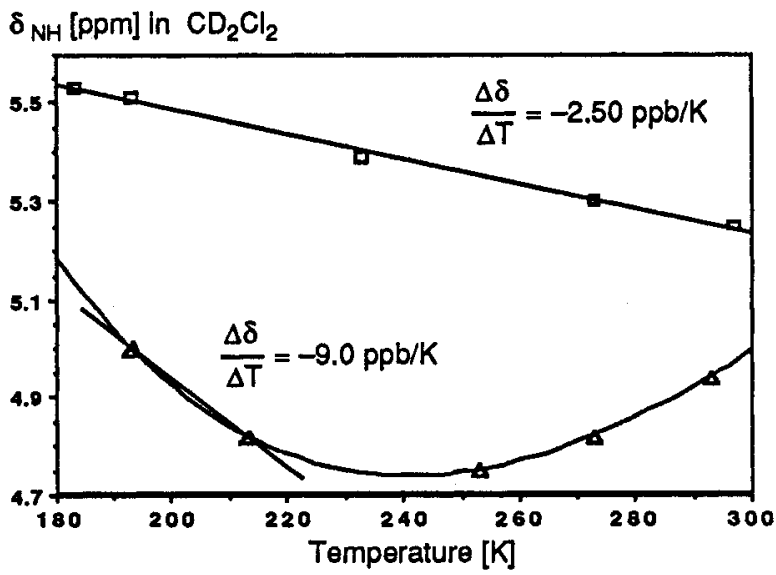

This unprecedented behaviour is explained by an intermolecular H-bond from the acetamido group to the glycosyl acceptor, as depicted in Scheme 32 (A). This H-bond competes with an intramolecular H-bond to the benzyloxy group (B). At low temperatures, rotation around the $\mathrm{N}-\mathrm{C}(2)$ bond is restricted, and the intramolecularly $\mathrm{H}$-bonded species dominates. Hence, formation of the $\alpha$-D-anomer is more strongly preferred at higher temperatures. The intramolecular H-bond should be much weaker - if it exists at all - for the GlcNAc-derived diazirine 111 and the carbene derived from it. This is evidenced by the temperature dependence of the chemical shift for the N-H signals of 11 and 111 
(Scheme 33). A linear dependence is found for 11. At temperatures below $210 \mathrm{~K}$, one finds a stronger dependence for 111, as expected for an intermolecularly $\mathrm{H}$-bonded species. At higher temperatures, the sign of the dependence is inverted: rotation of the NHAc group around the $\mathrm{N}-\mathrm{C}(2)$-bond brings the $\mathrm{NH}$ function into the deshielding cone of the strongly anisotropic diazirine ring (ref. 43). If this is so, then one expects a better $\alpha$-selectivity for glycosidations by 112, and this is indeed found, as shown in Scheme 34. The lower degree of stereoselectivity in the glycosidation of more strongly acidic alcohols reflects their lower degree of basicity, and their impaired ability to function as acceptors for the NH-..OH-bond.<smiles>Oc1ccccc1</smiles>

111

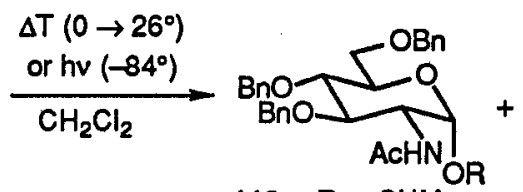

$112 \mathrm{a} \mathrm{R}=\mathrm{CHM}_{2}$

$112 b \quad \mathrm{~B}=\mathrm{CH}\left(\mathrm{CF}_{3}\right)_{2}$

112c $\mathrm{R}=\mathrm{C}_{6} \mathrm{H}_{4} \mathrm{NO}_{2}$

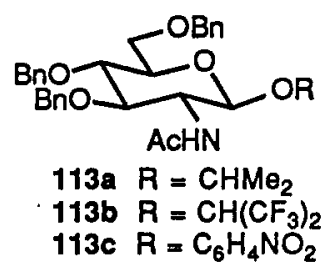

\begin{tabular}{|llll|}
\hline $\mathrm{ROH}$ & Conditions & $\%$ Glycosides & $\alpha: \beta$ \\
\hline $\mathrm{H}_{3} \mathrm{C}-\mathrm{OH}$ & $\mathrm{hv}$ & $70(+13 \% 114)$ & only $\alpha$ \\
$\mathrm{H}_{3} \mathrm{C}$ & & & \\
$\mathrm{F}_{3} \mathrm{C}-\mathrm{OH}$ & $\mathrm{hv}$ & 72 & $87: 13$ \\
$\mathrm{~F}_{3} \mathrm{C}$ & $\Delta \mathrm{T}$ & 59 & $71: 29$ \\
$\mathrm{O}_{2} \mathrm{~N}-\mathrm{hv}$ & 96 & $58: 42$ \\
\hline
\end{tabular}<smiles>CC(=O)OC1C2OC(C)=NC2C(OCc2ccccc2)C1OCc1ccccc1</smiles>

Scheme 35

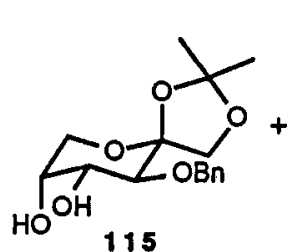

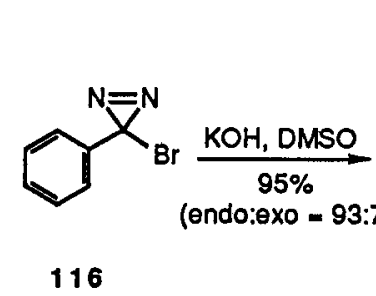

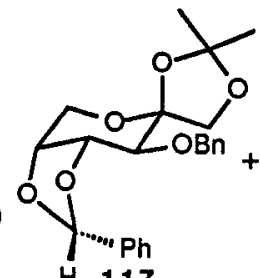

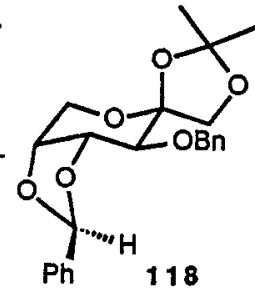<smiles>OC1C2OC3OC1C(O)C(O2)C3O</smiles>

119<smiles>[B]C1(c2ccccc2)N=N1</smiles><smiles>O=[Te]C(=O)O[Na]</smiles><smiles>CC(C)OC1C2OC3OC1C(OC(=O)C3c1ccccc1)C2O</smiles>

120<smiles>COC1C2COC(OC(c3ccccc3)O2)C(O)C1O</smiles>

121

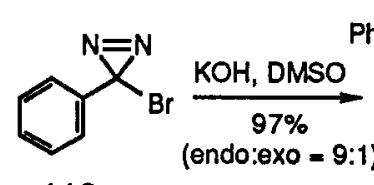

116 (endo:exo = 9:1)

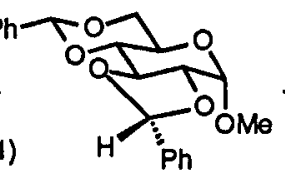

122

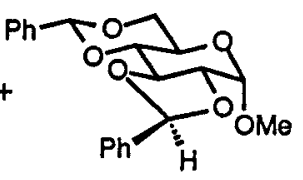

123

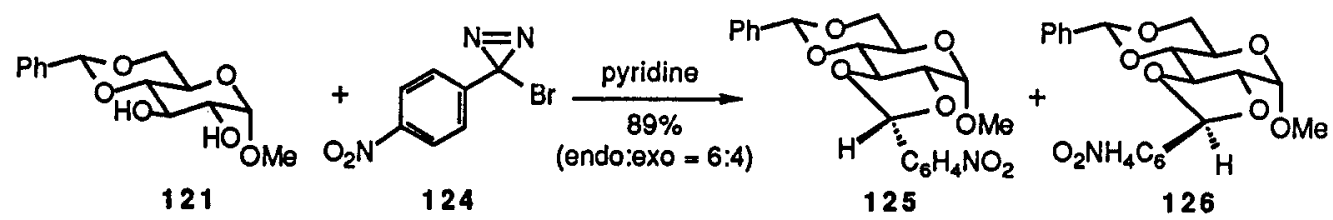

\section{OTHER REACTIONS}

The large number of transformations which are accessible via alkoxyalkyl carbenes, and, more specifically, via glycosylidene carbenes has been pointed out (ref. 10). Many have been realised outside the carbohydrate field (ref. 44), many remain to be explored. Thus, to the best of my knowledge, there is no preparatively applied intramolecular reaction of alkoxyalkyl carbenes. Such a reaction is realised in a new method for preparing benzylidene acetals (Schemes 35 and 36). Halodiazirines, such as $\mathbf{1 1 6}$ are prepared in about $50 \%$ yield from the commercially available benzamidines 
(Graham reaction; ref. 44, 45). Their exchange reaction with alkoxides (see ref. 46 and lit. quoted there) leads to alkoxydiazirines and further to alkoxycarbenes which may insert intramolecularly into O-H bonds. Thus, the 1,2-, and 1,3-cis diols 115 and 119 react with excess 116 to yield the benzylidene acetals $117 / 118$ and 120 in high yields and with a high diastereoselectivity. Similarly, the 1,2-trans diequatorial diol 121 reacts with 116 to afford the acetals 122/123 which have previously been obtained in low yields (ref. 47). 121 also reacted with the p-nitrophenyl diazirine 124 , obtained in about $25 \%$ from the corresponding amidinium salt (ref. 48,49 ), to give the acetals 125/126, again in high yields. Uridine (127) is protected as the known 2,3-O-benzylidene acetals 128 (ref. 50 ); the heterocycle is not attacked. The acetamido function does not interfere, as the GlcNAc-derivative 129 forms the acetals 130 in high yields. The basic reaction conditions (compare ref. 51) allow the protection of acid sensitive compounds, such as 6-O-trityl-glucal (131) (ref. 48). This method constitutes a valuable alternative to those requiring acidic conditions.

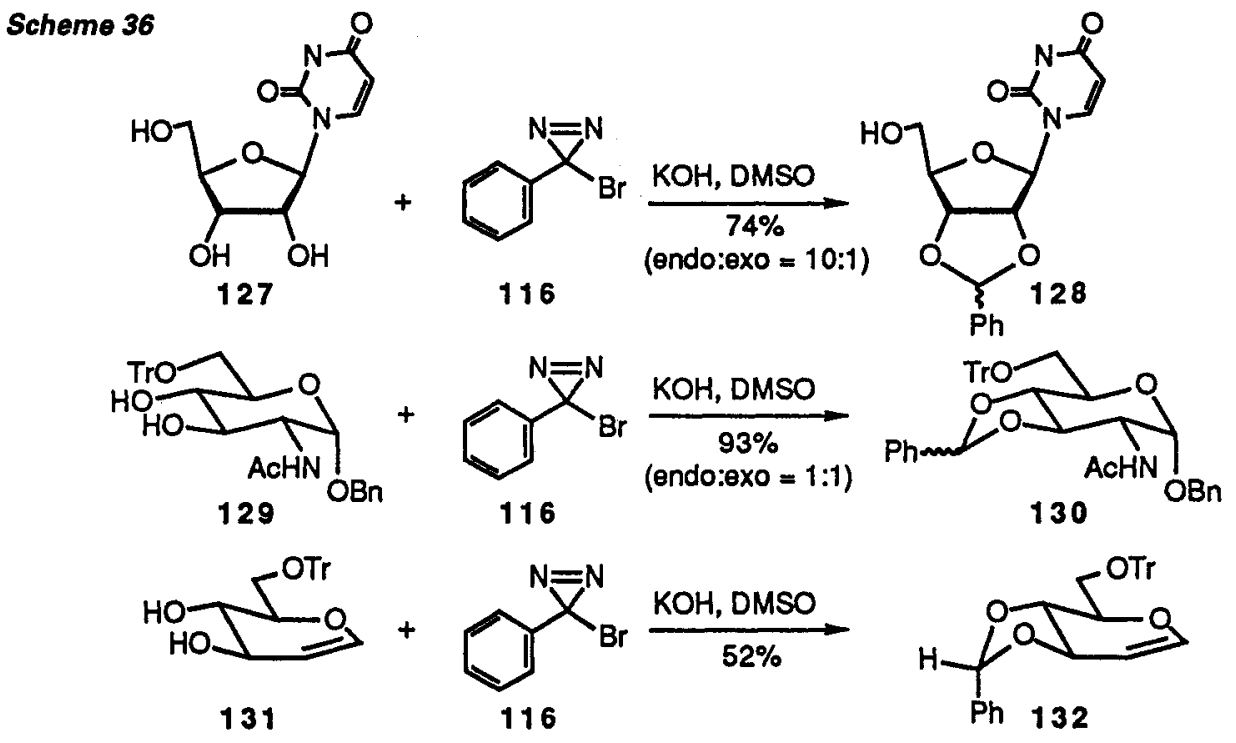

Scheme 37<smiles>CCOC(=O)C=C(C)c1ccccc1OC</smiles>

133<smiles>BrC1(c2ccccc2)N=N1</smiles>

116

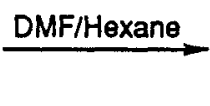<smiles>[R5]C1(C)CCCCC1=C</smiles>
135<smiles>CCOC(=O)[C@H]1Oc2ccccc2[C@@H](C)[C@@H]1c1ccccc1</smiles>

137

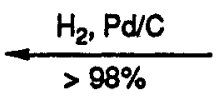<smiles>CCOC(=O)C=C(C)c1ccccc1OCc1ccccc1</smiles><smiles>CCOC(=O)C1(C)c2ccccc2OC1(c1ccccc1)c1ccccc1</smiles><smiles>[AsH2]</smiles><smiles>CCOC(=O)C1Oc2ccccc2C(C)=C1c1ccccc1</smiles>

The formation of C-C-bonds by intermolecular reactions of nucleophilic carbenes with acceptor substituted alkenes is well known, also for glycosylidene carbenes (ref. 12-14, 16, 52). However, we found no case of an intramolecular version of this process. To illustrate it, we treated the o-hydroxycinnamate 133 with the halodiazirine 116 (Scheme 37 ) and obtained $79 \%$ of the homobenzofuran 134 (compare ref. 53). At 120\%, 134 was reversibly transformed into its isomer 135 (presumably by way of a carbonyl oxide). At $200^{\circ}$, an electrocyclic opening of the cyclopropane ring took place and led in high yield to the benzopyran 136, which was hydrogenated to the all-cis product 137 (ref. 48 ). 
Scheme 38
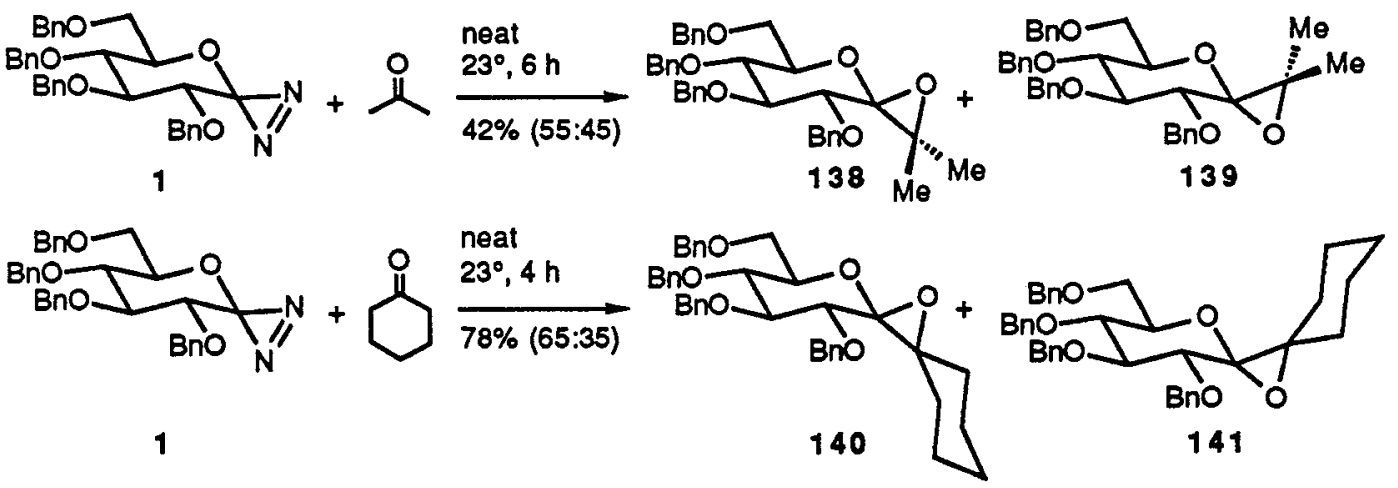

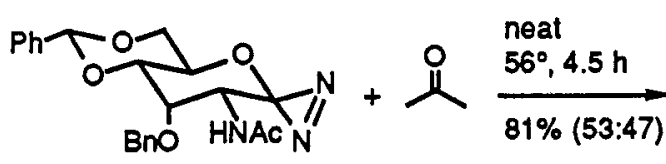

11

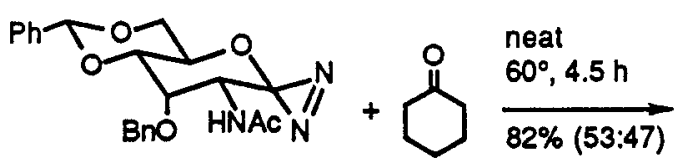

11

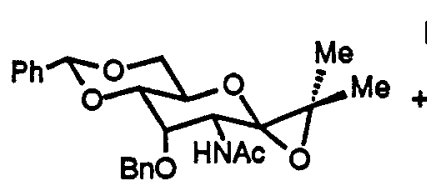

142

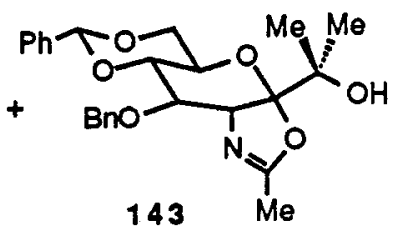

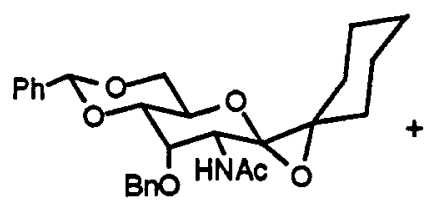

144

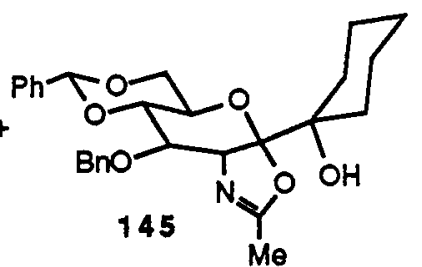

The nucleophilic character of glycosylidene carbenes is also evidenced by the reaction of the diazirines 1 and 11 with acetone and cyclohexanone (Scheme 38). Good yields are only obtained of relatively stable oxiranes and with a large excess of ketone. Stereoselectivity is low. Although we see no evidence for an isomerisation of the diazirines to diazo compounds (ref. 54), it cannot be excluded that such a process precedes attack on the ketones (ref. 55).

Scheme 39

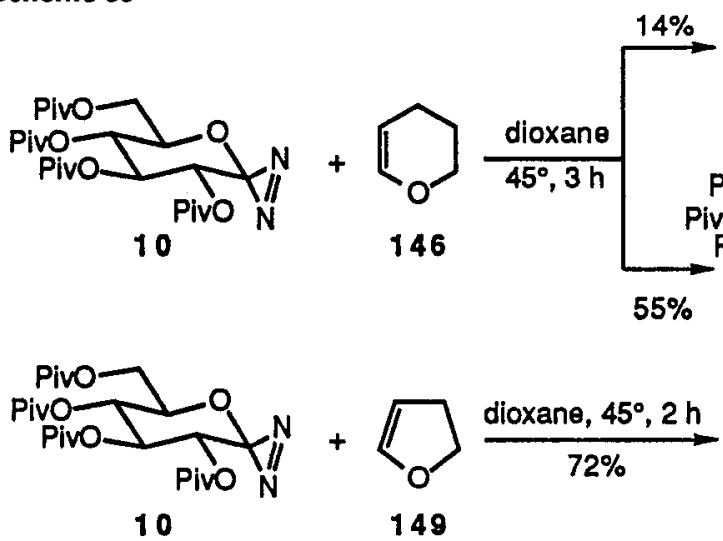

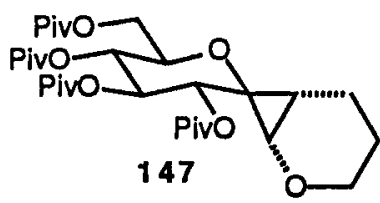

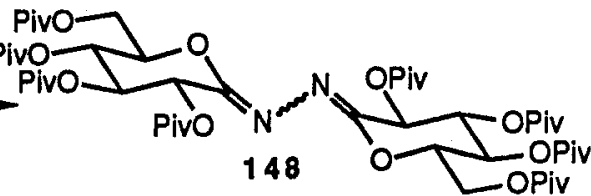
is also evidenced by the reaction of the pivaloyl-protected diazirine 10 with excess dihydropyran 146 and dihydrofuran 149 (Scheme 39; ref. 57). Dihydropyran is barely reactive enough, yielding only $14 \%$ of the dialkoxycyclopropane 147 and large amounts of the lactone azine 148, while the more reactive 149, a model compound for furanoid glycals, afforded 150 as a single product in good yields.

Cyclopropanation by the diazirines 1 and 10 also allowed the preparation of the first enantiomerically pure, monoglycosylated $\mathrm{C}_{60}$-buckminsterfullerene derivatives 152 and 153 in 55 and $54 \%$ (> 70\%, based upon recovered 151, Scheme 40 , ref. 58). This opens the way to a number of applications, both in the area of biological chemistry and material sciences. 


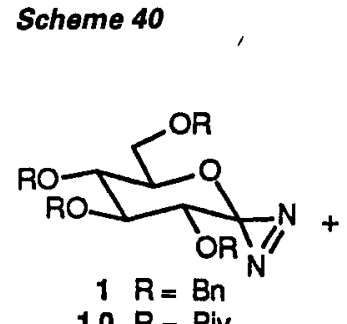

$10 \mathrm{R}=\mathrm{Piv}$

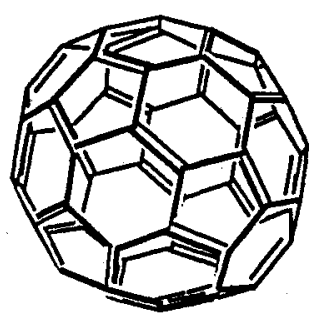

$151\left(\mathrm{C}_{60}\right)$

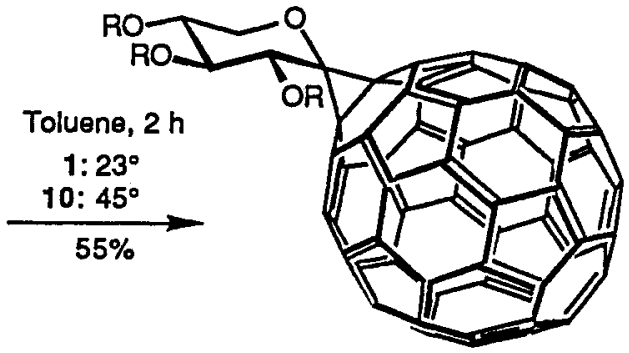

$152 \mathrm{R}=\mathrm{Bn}$

$153 \mathrm{R}=\mathrm{Piv}$

\section{Acknowledgement}

I sincerely thank Dr. Bruno Bernet, Dr. Eva Bozo, Karin Briner, Dr. Preeti Dhar, Chunbao Li, Jean-Luc Maloisel, Sissi Mangholz, Dr. Pulla R. Muddasani, Dr. Luigi Panza, Dr. Yoshikazu Takahashi, Peter Uhlmann, Christian Waldraff, and Christian Witzig for their enthusiasm and for their excellent collaboration, Prof. Dr. François Diederich and Dr. Carlo Thilgen (ETH Zürich) for a stimulating collaboration in the $\mathrm{C}_{60}$-buckminsterfullerene project, and Dr. Anthony Linden for many X-ray analyses. I gratefully acknowledge the generous financial contributions by the Swiss National Science Foundation and by F. Hoffmann La Roche AG, Basel.

\section{REFERENCES}

1. For recent reviews, cf. a) R.R. Schmidt, Pure Appl. Chem. 1989, 61, 1257-1270. b) H. Kunz, Angew. Chem. 1987, 99, 297-311. c) P. Fügedi, P.J. Garegg, H. Lönn, Th. Norberg, Glycoconjugate J. 1987, 4, 97-108. For a compilation of reviews, cf. d) R.W. Binkley, J. Carbohydr. Chem. 1988, 7, vii-xi. For examples of alternative methods, cf. e) Y.E. Tsvetskov, W. Klotz, R.R. Schmidt, Liebigs Ann. Chem. 1992, 371-375. f) A.G.M. Barrett, B.C.B. Bezuidenhoudt, A.R. Howell, A.C. Lee, M.A. Russell, J. Org. Chem. 1989, 54 , 2275-2277. g) D. Kahne, D. Yang, J.J. Lim, R. Miller, E. Paguaga, J. Am. Chem. Soc. 1988, 110, 87168717. h) A. Boschetti, L. Panza, F. Ronchett, G. Russo, J. Chem. Soc., Perkin Trans. 1 1988, 3353-3357. i) R.U. Lemieux, T.L. Nagabhushan, K. James, Can. J. Chem. 1973, 51, 1-6. j) R.U. Lemieux, Y. Ito, K. James, T.L. Nagabhushan, Can. J. Chem. 1973, 51, 7-18. k) R.U. Lemieux, T.L. Nagabhushan, K.J. Clemetson, L.C.N. Tucker, Can. J. Chem. 1973, 5i, 53-66.

2. For some examples, $c f .1$ and a) Sh. Suda, T. Mukaiyama, Chem. Lett. 1991, 431-434. b) T. Mukaiyama, K. Matsubara, Sh. Suda Chem. Lett. 1991, 981-984. c) S. Hashimoto, T. Honda, S. Ikegami, Tetrahedron Lett. 1991, 32, 1653-1654. d) J.C. Lopez, B. Fraser-Reid, J. Chem. Soc., Chem. Commun. 1991, 159-161. e) A.J. Ratcliffe, B. Fraser-Reid, J. Chem. Soc., Perkin Trans. 1 1990, 747-750. f) T. Mukaiyama, S. Suda, Chem. Lett. 1990, 1143-1146. g) Sh. Hashimoto, T. Honda, Sh. Ikegami, Heterocycles 1990, 30, 775-778. h) Y. Leblanc, B.J. Fitzsimmons, Tetrahedron Lett. 1989, 30, 2889-2892. i) Sh. Koto, N. Morishima, M. Uchino, M. Fukuda, M. Yamazaki, S. Zen, Bull. Chem. Soc. Jpn. 1988, 61, 3943-3950. j) N. Chida, M. Ohtsuka, S. Ogawa, Chem. Lett. 1988, 969-972. k) R. Noyori, I. Kurimoto, J. Org. Chem. 1986, 51,4320 4322. 1) F. Paquet, P. Sinay, Tetrahedron Lett. 1984, 25, 3071-3074. m) L.-F. Tietze, R. Fischer, H.-J. Guder, Tetrahedron Lett. 1982, 23, 4661-4664. n) J.M. Lacombe, A.A. Pavia, J.M. Rocheville, Can. J. Chem. 1981, 59, 473-481. o) S. Hanessian, Ch. Baquet, N. Lehong, Carbohydr. Res. 1980, 80, C17-C22. p) H. Tsutsumi, Y. Kawai, Y. Ishido, Chem. Lett. 1978, 629-632. q) T. Mukaiyama, S. Shoda, T. Nakatsuka, K. Narasaka, Chem. Lett. 1978, 605-608. r) O. Larm, Carbohydr. Res. 1975, 43, 192-194.

3. a) A. Marra, F, Gauffeny, P. Sinay, Tetrahedron 1991, 47, 5149-5160. b) A. Hasegawa, T. Nagahama, H. Ohki, K. Hotta, H. Ishida, M. Kiso, J. Carbohydr. Chem. 1991, 10, 493-498. c) A. Marra, J.-M. Mallet, C. Amatore, P. Sinay, Synlett 1990, 572-574. d) A. Marra, P. Sinay, Carbohydr. Res. 1990, 195, 303-308. e) R.R. Schmidt, M. Behrendt, A. Toepfer, Synlett 1990, 694-696. f Y. Ito, T. Ogawa, Tetrahedron Lett. 1987, $28,4701-4704$.

4. H. Paulsen, Angew. Chem. 1982, 94, 184-201.

5. a) B. Fraser-Reid, Z. Wu, U.E. Udodong, H. Ottosson, J. Org. Chem. 1990, 55, 6068-6070. b) G.H. Veeneman, S.H. van Leeuwen, J.H. van Boom, Tetrahedron Lett. 1990, 31, 1331-1334. c) G.H. Veeneman, J.H. van Boom, Tetrahedron Lett. 1990, 31, 275-278. d) R.L. Halcomb, S. Danishefsky, J. Am. Chem. Soc. 1989, 111, 6661-6666. e) D.R. Mootoo, P. Konradsson, U. Udodong, B. Fraser-Reid, J. Am. Chem. Soc. 1988, 110, 5583-5586.

6. a) S.P. Douglas, D.M. Whitfield, J.J. Krepinsky, J. Am. Chem. Soc. 1991, 113, 5095-5097. b)A. Malik, H. Bauer, J. Tschakert, W. Voelter, Chem.-Zeitg. 1990, 144, 371-375. c) Sh-H. L. Chiu, L. Anderson, Carbohydr. Res. 1976, 50, 227-238. d) J.M. Fréchet, C. Schuerch, J. Am. Chem. Soc. 1976, 94, 604-609.

7. For some examples of regioselective glycosylation of diols, cf. a) S. Ogawa, K. Nishi, Carbohydr. Res. 1992, 229, 117-129. b) K.C. Nicolaou, C.W. Hummel, Y. Iwabuchi, J. Am. Chem. Soc. 1992, 114, 3126-3128. c) J.-L. Maloisel, A. Vasella, B.M. Trost, D.L. van Vranken J. Chem. Soc., Chem. Commun. 1991, 1099-1101. d) R.R. Schmidt, W. Klotz, Synlett 1991, 168-170. e) C. Cruzado, M. Bernabe, M. Martin-Lomas, 
Carbohydr. Res. 1990, 203, 296-301. f) H. Paulsen, Ch. Krogman, Carbohydr. Res. 1990, 205, 31-44. g) S.H. Khan, S.A. Abbas, K.L. Matta, Carbohydr. Res. 1990, 205, 385-397. h) H. Baumann, B. Erbing, P.E. Jansson, L. Kenne, J. Chem. Soc., Perkin Trans. 1 1989, 2145-2151. i) H. Paulsen, W. Rauwald, U. Weichart, Liebigs Ann. Chem. 1988, 75-86. j) S. Sato, Y. Ito, T. Ogawa, Tetrahedron Lett. 1988, 29, 47594762. k) P. Fügedi, W. Birberg, P.J. Garegg, A. Pilotti, Carbohydr. Res. 1987, 164, 297-312. 1) J. Alais, A. Veyrieres, Tetrahedron Lett. 1987, 28, 3345-3348. m) H. Paulsen, K.-M. Steiger, Carbohydr. Res. 1987, 169, 105-125. n) K. Okamoto, T. Kondo, T. Goto, Tetrahedron 1987, 43, 5909-5918 and 5919-5928. o) K. Okamoto, T. Kondo, T. Goto, Bull. Chem. Soc. Jpn. 1987, 60, 631-636 and 637-643. p) H. Paulsen, U. von Dessen, Carbohydr. Res. 1986, 146, 147-153. q) A. Hasegawa, J. Nakamura, M. Kiso, J. Carbohydr. Chem. 1986, 5, 11-19 and 21-31. r) K.K. Sadozai, T. Nukada, Y. Ito, Y. Nakahara, T. Ogawa, A. Kabata, Carbohydr. Res. 1986, 157, 101-123. s) A. Fernandez-Mayoralas, M. Martin-Lomas, Carbohydr. Res. 1986, 154, 93-101. t) A. Maranduba, A. Veyrières, Carbohydr. Res. 1986, 151, 105-119. u) K. Leontein, N. Nilsson, Th. Norberg, Carbohydr. Res. 1985, 144, 231-240. v) H. Paulsen, M. Paal, Carbohydr. Res. 1985, 137, 39-62. w) S.S. Rana, K.L. Matta, Carbohydr. Res. 1983, 116, 71-81. x) N. Kochetkov, V.I. Torgov, N.N. Malysheva, A.S. Shaskov, E.M. Klimov, Tetrahedron 1980, 36, 1227-1230. y) J. Jacquinet, D. Duchet, M. Milat, P. Sinaỳ, J. Chem. Soc., Perkin Trans. 1 1981, 326-330. z) C. Auge, A. Veyrières, J. Chem. Soc., Perkin Trans. 1 1979, 1825-1832. A) S. Hanessian, J. Banoub, Carbohydr. Res. 1977, 53, C13- C16. B) G. Röhle, H. Breuer, Hoppe-Seyler's Z. Physiol. Chem. 1974, 355, 490-494. For examples of regioselective glycosylation of triols, cf. C) J. Tamura, S. Horito, J. Yoshimura, H. Hashimoto, Carbohydr. Res. 1990, 207, 153-165. D) R.L. Thomas, A.K. Sarkar, K. Kohata, S.A. Abbas, K.L. Matta, Tetrahedron Lett. 1990, 31 , 2825-2828. E) T. Murase, H. Ishida, M. Kiso, A. Hasegawa, Carbohydr. Res, 1988, 184, C1-C4.

8. For glycosylations under high pressure or at elevated temperature, $c f$. a) M. Nishizawa in "Studies in Natural Products Chemistry" , Atta-ar-Rahman, ed., Elsevier, Amsterdam, 1991, Vol. 8, pp. 359-371. b) M. Sasaki, Y. Gama, M. Yasumoto, Y. Ishigami, Tetrahedron Lett. 1990, 31, 6549-6552. c) M. Nishizawa, Y. Kan, W. Shimomoto, H. Yamada, Tetrahedron Lett. 1990, 31, 2431-2434. d) M. Nishizawa, Y. Kan, H. Yamada, Chem. Pharm. Bull. 1989, 37, 565-567.

9. K. Briner, A. Vasella, Helv. Chim. Acta 1989, 72, 1371-1382.

10. A. Vasella, Pure Appl. Chem. 1991, 63, 507-518.

11. For leading references to the insertion of (oxy) carbenes into $O-H$ bonds of alcohols, $c f$. a) X.-M. Du, H. Fan, J.L. Goodman, M.A. Kesselmayer, K. Krogh-Jespersen, A. LaVilla, R.A. Moss, S. Shen, R.S. Sheridan, J. Am. Chem. Soc. 1990, 112, 1920-1926. b) W. Kirmse, G. Hömberger, J. Am. Chem. Soc. 1991, 113, 3925-3934. c) W. Kirmse, J. Kilian, S. Steenken, J. Am. Chem. Soc. 1990, 112 , 6399-6400. d) W.Kirmse, K. Kund, J. Org. Chem. 1990, 55, 2325-2332. e) M. Azadi-Ardakani, G.C. Loftus, A.M.M. Mjalli, R.F. Newton, S.M. Roberts, J. Chem. Soc., Chem. Commun. 1989, 1709-1711. f) M.C. Pirrung, V.K. Chang, C.V. DeAmicis, J. Am. Chem. Soc. 1989, 111, 5814-5831. g) M.T.H. Liu, R. Subramanian, J. Chem. Soc., Perkin Trans. 2 1988, 15-17, h) R.A. Moss, S. Shen, M. Wlostowski, Tetrahedron Lett. 1988, 29, 64176420. i) R.A. Moss, J. Wlostowska, Sh. Shen, K. Krogh-Jespersen, A. Matro, J. Am. Chem. Soc. 1988, 110 , 4443-4444. j) M.T.H. Liu, R. Subramanian, J. Chem. Soc., Perkin Trans. 21986 1233-1240. k) S. Oikawa, M. Tsuda, J. Am. Chem. Soc. 1985, 107, 1940-1946. 1) J.J. Zupancic, P.B. Grasse, S.C. Lapin, G.B. Schuster, Tetrahedron 1985, 41, 1471-1478. m) M.T.H. Liu, R. Subramanian, J. Chem. Soc., Chem. Commun. 1984, 1062-1064. n) P.M. Warner, I.-S. Chu, J. Am. Chem. Soc. 1984, 106, 5366-5367. 0) W. Kirmse, P. Van Chiem, P.G. Henning, J. Am. Chem. Soc. 1983, 105, 1695-1696. p) D. Griller, M. Liu, J.C. Scaiano, J. Am. Chem. Soc. 1982, 104, 5549-5553. q) P. Yates, R.O. Loutfy, Acc. Chem. Res. 1975, 8, 209-216. r) D. Bethell, R.D. Howard, J. Chem. Soc. (B) 1969, 745-748. s) W. Kirmse, Liebigs Ann. Chem. 1963, 666, 9-16.

12. S.E. Mangholz, A. Vasella, Helv. Chim. Acta 1990, 73, $2100-2111$.

13. L. Somsak, J.-P. Praly, G. Descotes, Synlett 1992, 119-120.

14. a) J.-P. Praly, Z. El Kharraf, G. Descotes, J. Chem. Soc., Chem. Commun. 1990, 431-432. b) J.-P. Praly, Z. E1 Kharraf, G. Descotes, Tetrahedron Lett. 1990, 31, 4441-4442.

15. L. Panza, Ch. Waldraff, A. Vasella, in preparation.

16. A. Vasella, Ch. Witzig, R. Husi, Helv. Chim. Acta 1991, 74, 1362-1372.

17. S.E. Mangholz, A. Vasella, in preparation.

18. K. Briner, A. Vasella, Helv. Chim. Acta 1992, 75, 621-637.

19. a) J. Greiner, A. Manfredi, J.G. Riess, Nouv. J. Chim. 1989, 13, 247-254. b) J. Greiner, A. Milius, J.G. Riess, Tetrahedron Lett. 1988, 29, $2193-2194$.

20. a) G. Wulff, W. Schmidt, Carbohydr. Res. 1977, 53, 33-46. b) B. Helferich, J. Zirner, Chem. Ber. 1963, $96,374$.

21. A. Vasella, K. Briner, M. Soundararajan, M.S. Platz, J. Org. Chem. 1991, 56, 4741-4747.

22. a) F. Hibbert, J. Emsley, Adv. Phys. Org. Chem. 1990, 26, 255-379. b) F. Hibbert, Adv. Phys. Org. Chem. 1986, 22, 113-212.

23. a) R.U. Lemieux, A.R. Morgan, Can. J. Chem. 1965, 43, 2205-2213. b) A.C. West, C. Schuerch, J. Am. Chem. Soc. 1973, 95, 1333-1335. c) F.J. Kronzer, C. Schuerch, Carbohydr. Res. 1974, 33, 273-280. d) R. Eby, C. Schuerch, Carbohydr. Res. 1975, 39, 33-38.

24. Y. Takahashi, A. Vasella, Helv. Chim. Acta, in the press.

25. For a leading reference, see M.T. Liu, Chem. Soc. Rev. 1982, 127-140.

26. K. Briner, A. Vasella, Ch. Waldraff, Ch. Witzig, in preparation.

27. B. Fraser-Reid, Z. Wu, W. Andrews, E. Skowronski, J.P. Bowen J. Am. Chem. Soc. 1991, 113, $1434-1435$.

28. A. Linden, A. Vasella, Ch. Witzig, Helv. Chim. Acta, submitted. 
29. a) For a leading reference, see M.T.H. Liu, K. Ramakrishnan, Tetrahedron Lett. 1977, 18, 3139-3142. Also compare b) R.A. Moss, G.-J. Ho, J. Am. Chem. Soc. 1990, 112, 5642-5644. c) R.A. Moss, J. Wlostowska, Tetrahedron Lett. 1988, 29, 2559-2562. d) M.T.H. Liu, N. Sundararajan, S.M. Anand, T. Ibata, Tetrahedron Lett. 1987, 28, 1011-1014. e) M.A. Kesselmayer, R.S. Sheridan, J. Am. Chem. Soc. 1986, 108, 99-107. f) N.P. Smith, J. Chem. Soc., Perkin Trans. 2 1979, 1298-1308. g) K. Mackenzie, in "The chemistry of the hydrazo, azo and azoxy groups", Ed. S. Patai, J. Wiley, NewYork, 1975, Pt. 1, Chapter 11, pp. 329-436.

30. G.A. Jeffrey, W. Saenger, "Hydrogen Bonding in Biological Structures", Springer Verlag, Berlin, 1991.

31. G.A. Jeffrey, Carbohydr. Res. 1973, 28, 233-241.

32. H. Hönig, H. Weidmann, Carbohydr. Res. 1979, 73, 260-266.

33. Y. Takahashi, personal communication.

34. a) P. Uhlmann, A. Vasella, in preparation. b) A. Linden, personal communication.

35. Y. Park, H. Kim, G. Jeffrey, Acta Crystallogr., Sect. B 1971, 27, 220-227.

36. a) C.W. Jefford, B. Waegell, Tetrahedron Lett. 1963, 1981-1985. b) J.-F. Biellmann, R. Hanna, G. Ourisson, C. Sandris, B. Waegell, Bull. Soc. Chim. France 1960, 1429-1430.

37. E. Bozo, A. Vasella, in preparation.

38. a) R.U. Lemieux, K.J.B. Hendriks, R.V. Stick, K. James, J. Am. Chem. Soc. 1975, 97, 4056-4062. b) R.U. Lemieux, H. Driguez, J. Am. Chem. Soc. 1975, 97, 4063-4068. c) R.U. Lemieux, H. Driguez, J. Am. Chem. Soc. 1975, 97, 4069-4075. d) R.U. Lemieux, D.R. Bundle, D.A. Baker, J. Am. Chem. Soc. 1975, 97, 4076-4083.

39. P.R. Muddasami, E. Bozo, A. Vasella, in preparation.

40. E. Bozo, P.R. Muddasani, P. Uhlmann, A. Vasella, in preparation.

41. K. Briner, J.-L. Maloisel, A. Vasella, in preparation.

42. A. Vasella, Ch. Witzig, in preparation.

43. J.J. Uebel, J.C. Martin, J. Am. Chem. Soc. 1964, 86, 4618-4623.

44. M.T. Liu, "Chemistry of Diazirines", CRC Press, Boca Raton, Florida, 1987.

45. W.H. Graham, J. Am. Chem. Soc. 1965, 87, 4396-4397.

46. X. Creary, Acc. Chem. Res. 1992, 25, 31-38.

47. a) J. Thiem, J. Elvers, Carbohydr. Res. 1978, 60, 63-73. b) P.J. Garegg, C.-G. Swain, Acta Chem. Scand. 1977, 26, 3895-3901.

48. Ch. $\mathrm{Li}, \mathrm{A}$. Vasella, in preparation.

49. X. Creary, A.F. Sky, G. Phillips, J. Org. Chem. 1990, 55, 2005-2011.

50. M.M. Ponpipom, S. Hanessian, Can. J. Chem. 1972, 50, 246-252.

51. P.J. Garegg, C.-G. Swain, "Methods in Carbohydrate Chemistry", Eds. R.L. Whistler and J.N. BeMiller, Academic Press, New York, 1980, Vol. VIII, p. 317-319.

52. A. Vasella, Ch.A.A. Waldraff, Helv. Chim. Acta 1991, 74, 585-593.

53. E. Schmitz, H. Sonnenschein, Z. Chem. 1987, 27, 171.

54. a) R.A. Moss, T. Zdrojewski, K. Krogh-Jespersen, Tetrahedron Lett. 1991, 32, 1925-1928. b) R.S. Sheridan, R.A. Moss, B.K. Wilk, S. Shen, M. Wostowski, M.A. Kesselmayer, R. Subramanian, O. Kmiecik-

Lawrynowicz, K. Krogh-Jespersen, J. Am. Chem. Soc. 1988, 110, 7563-7564. c) R.A. Moss, Sh. Shen, L.M. Hadel, G. Kmiecik-Lawrynowicz, J. Wlostowska, K. Krogh-Jespersen, J. Am. Chem. Soc. 1987, 109, 4341-4349. d) M.A. Kesselmayer, R.S. Sheridan, J. Am. Chem. Soc. 1986, 108, 844-845. e) N.P. Smith, J. Chem. Soc., Perkin Trans. 2 1979, 1298-1308.

55. W. Kirmse, G. Hellwig, Ph. Van Chiem, Chem. Ber. 1986, 119, 1511-1524.

56. A. Vasella, G. Baudin, L. Panza, Heteroatom Chem. 1991, 2, 151-161.

57. A. Vasella, Ch.A.A. Waldraff, in preparation.

58. A. Vasella, P. Uhlmann, Ch.A.A. Waldraff, F. Diederich, C. Thilgen, Angew. Chem., accepted. 